\title{
COLORS' SYMBOLISM IN THE MODERN OMANI POETRY: AN ANALYTICAL DESCRIPTIVE STUDY
}
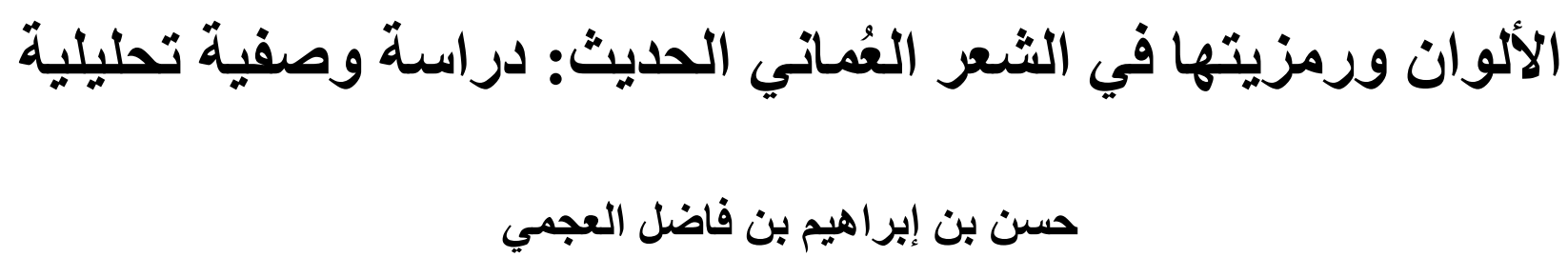

Hassan Ibrahim Fadhil Ajmi ${ }^{1 *}$, Majdi Bin Haji Ibrahim ${ }^{2}$ and Yasir Bin Ismail ${ }^{3}$

${ }^{1}$ Ph.D. Candidate in Arabic Linguistic Studies Kuliyyah of Islamic Revealed Knowledge and Human Sciences, International Islamic University Malaysia (IIUM), ha44an@hotmail.com

${ }^{2}$ Prof. Dr. Kuliyyah of Islamic Revealed Knowledge and Human Sciences, International Islamic University Malaysia (IIUM), majdi@iium.edu.my

${ }^{3}$ Dr. Senior Lecturer, Kuliyyah of Islamic Revealed Knowledge and Human Sciences, International Islamic University Malaysia (IIUM), dryasir@iium.edu.my

${ }^{*}$ Corresponding Author

\begin{abstract}
This study discussed colors and their symbolism in Omani poetry, through the phenomenon of man's interest in colors, and using them for various expressions, joyful, cheerful, and sad. The problem arose that poets use colors according to their perceptions because of their suggestive and original value in building the poetic image, so the poet depends in use of color on specific colors in order, according to the strength of its appearance. In most cases, we find that the color is not mentioned in what was described to it, but rather reveals the poet's feeling. Being a source of vitality, activity, comfort and reassurance, and a symbol of different feelings of sadness and pleasure. The objectives of the study: To show the rooting of color in Arab poetry, in the past and present. Keep track of color tones and attributes. Then a discussion and analysis of the implications of the use of color in Omani poetry. Through the descriptive and analytical approach, the study reached the following results: Arab poets, in the past and present, knew colors and used them in their poetry, but their knowledge of color was limited in the ancient era, but recently colors have spread to all aspects of our contemporary life, and it has turned into a means of seduction and excitement, and into $\mathrm{A}$ suggestive language that expresses itself with its symbols, and its connotations that vary according to the different colors and their effects, and Omani poets have distinguished themselves in employing colors in their poetry better than others, and examples of this are what we found in the poetry of Al-Khalili, Hilal bin Saeed Al-Omani, Jumah Al-Hanjri, Al-Tai, and others.
\end{abstract}

Keywords: colors, symbolism, Omani poetry. 


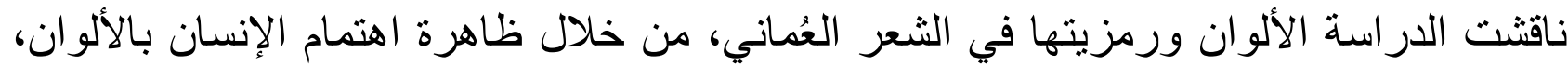

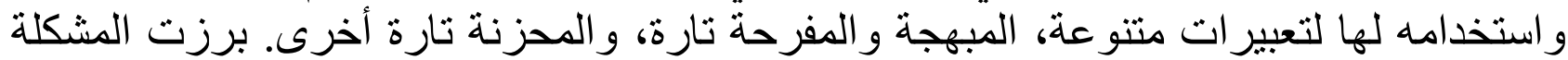

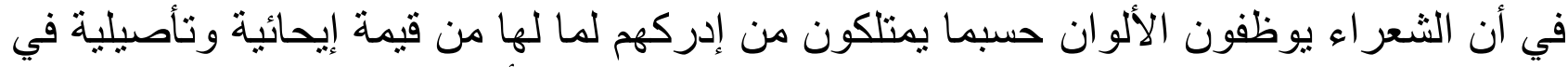

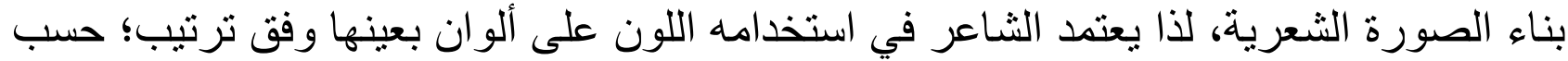

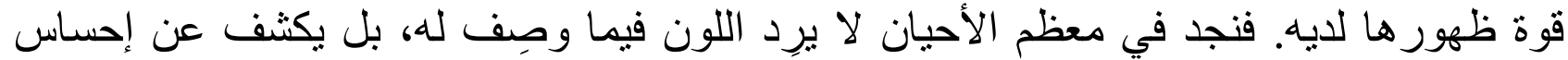

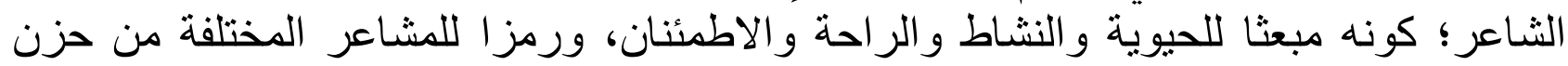

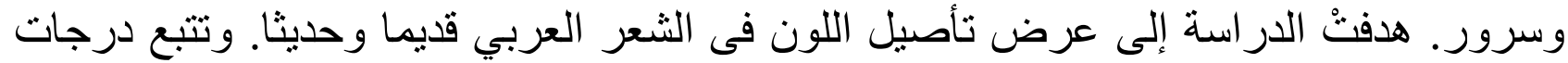

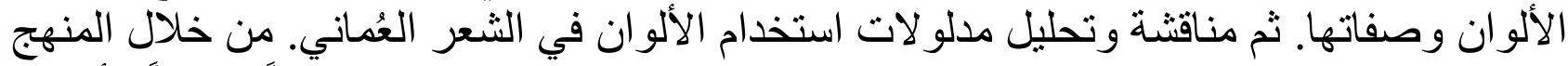

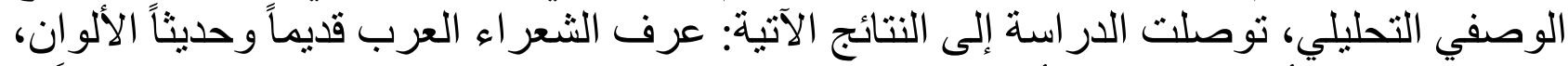

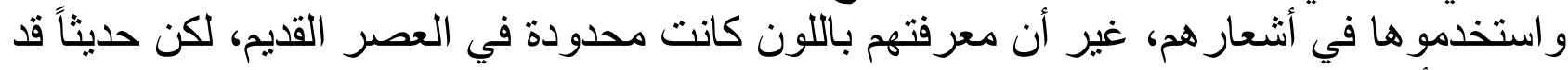

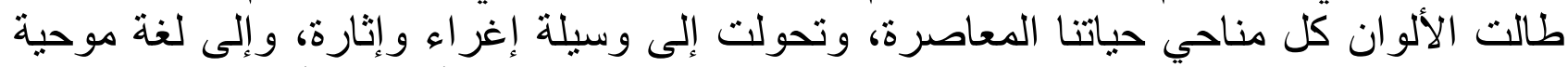

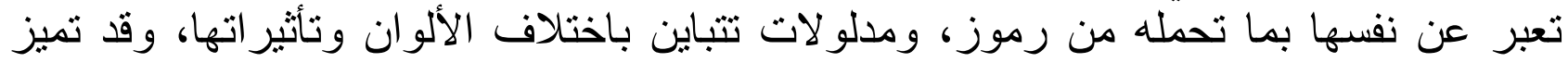

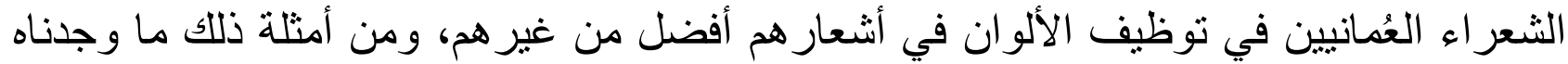

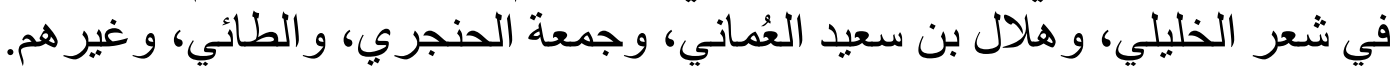

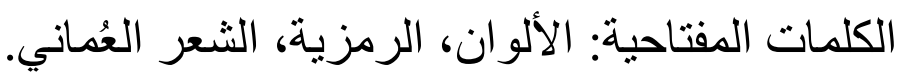

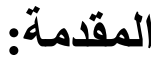

تعدُّ لغة الألوان من أهم أنواع التشكيل اللغوي في الثعر الحديث، إذْ تمثل أهمية كبيرة لا يستهان إنهان

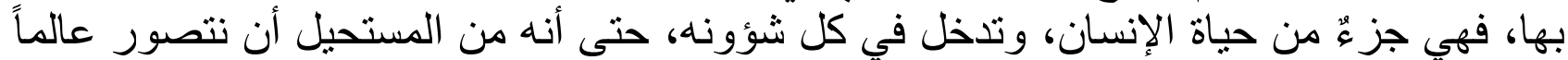

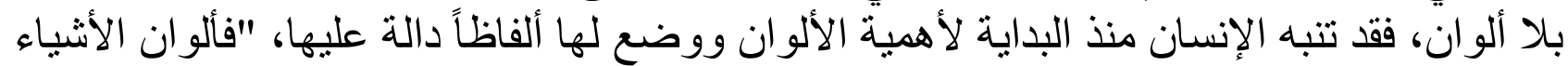

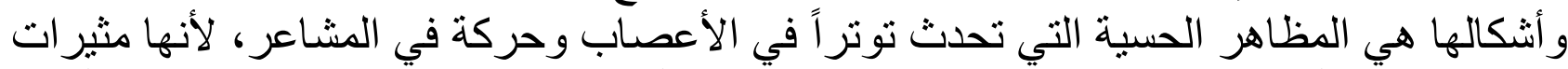

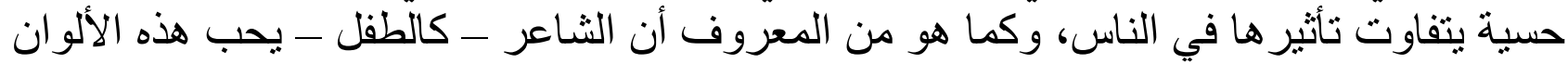

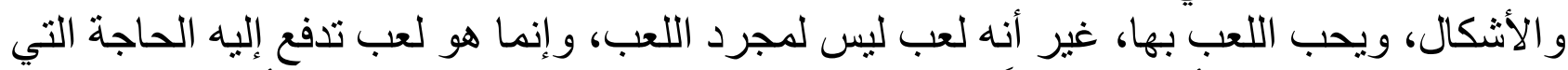

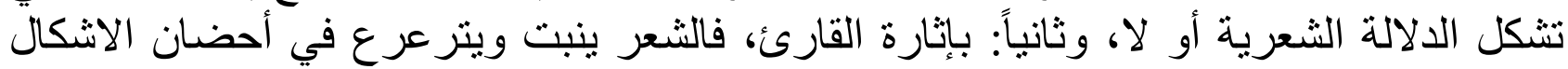

$$
\text { و الألوان" (روباش، 2017: 169). }
$$

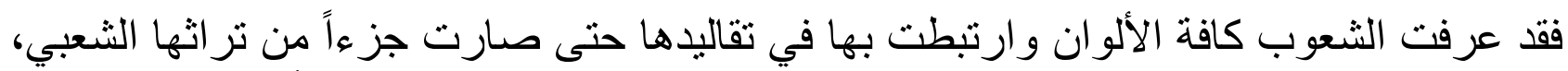

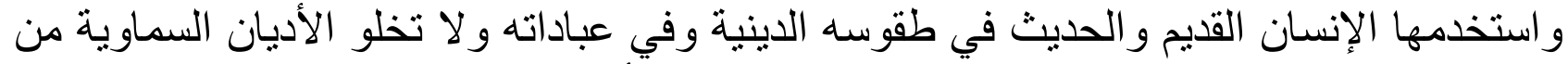

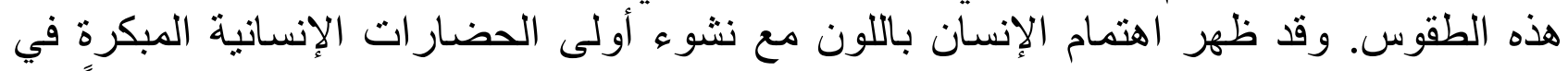

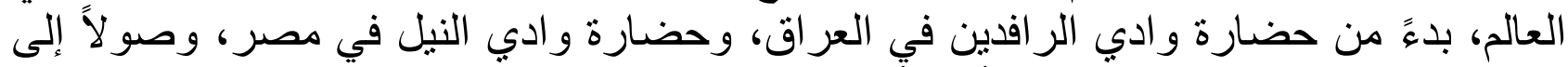

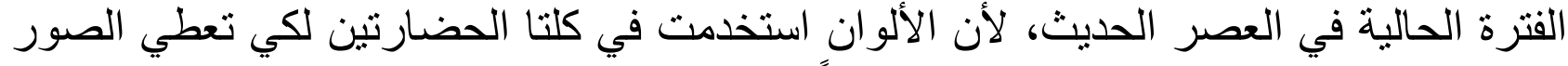
و المنحوتات الدينية في المعابد والقصور جمالاً وقدية وهيبه في نفس من بر الها لهن (حسن، 2018:

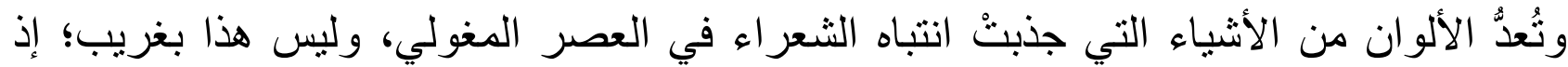

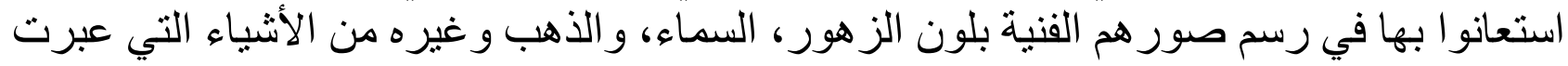




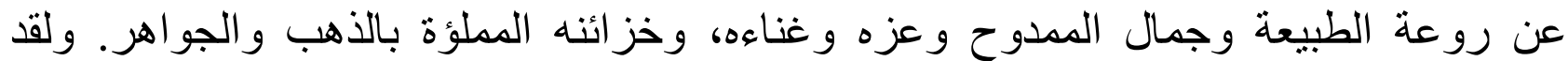

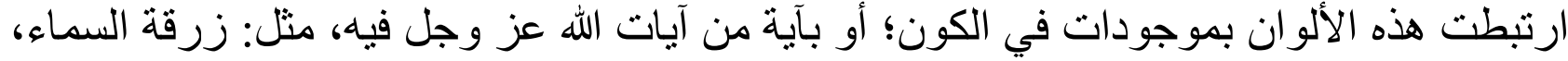
وظلمة الليل، وبياض النهار وذهبية الثمس وغير ذالكئ ذلك (تحمد، 2016: 141).

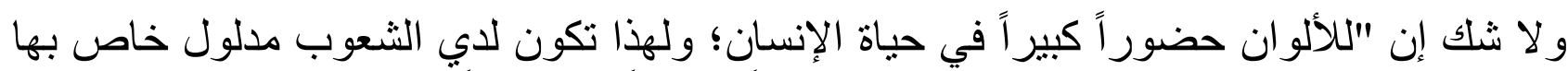

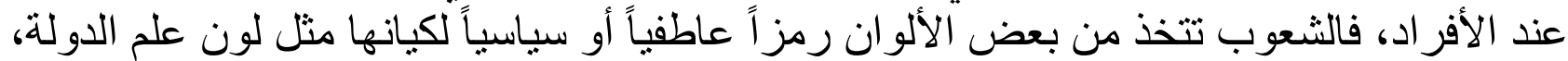

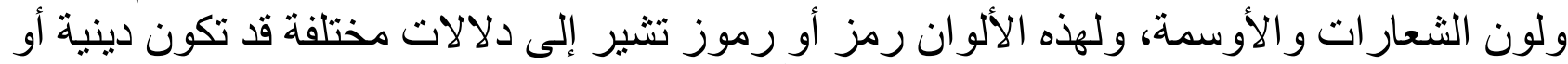

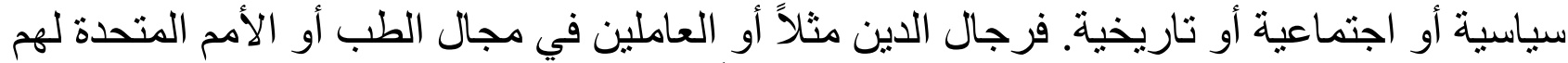

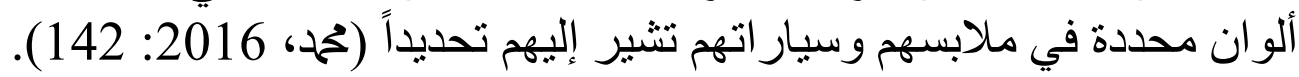

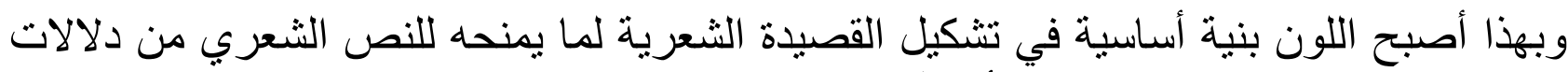

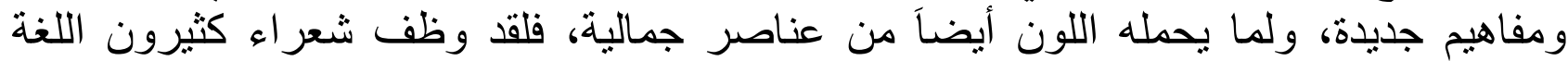

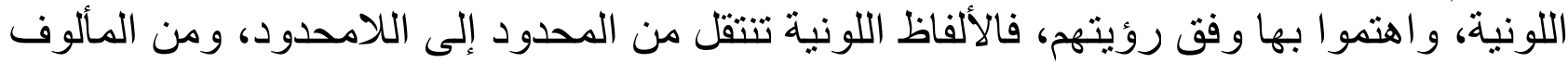

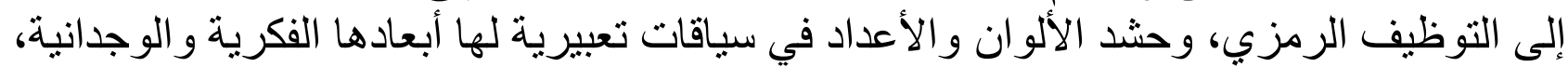

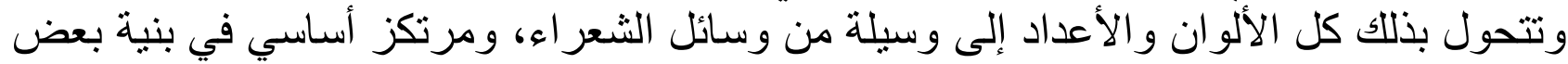
القصائد(روباش، 2017: 169).

تعريف اللون:

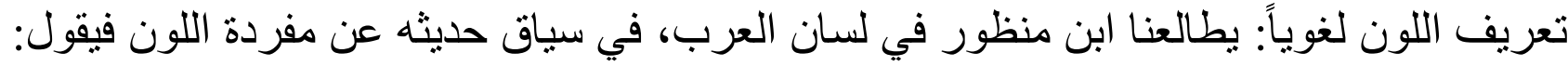

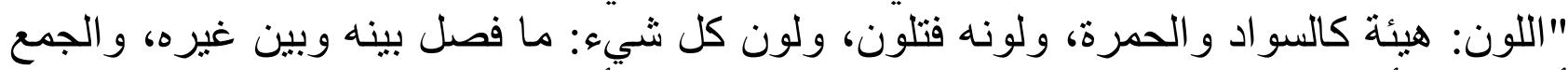

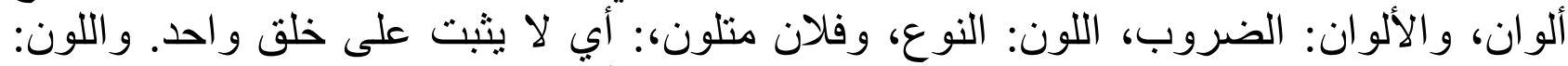

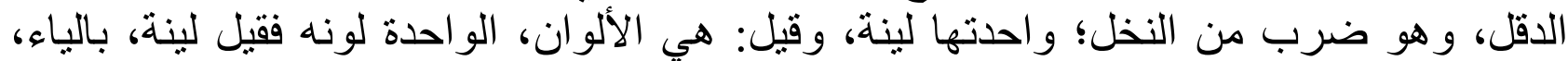

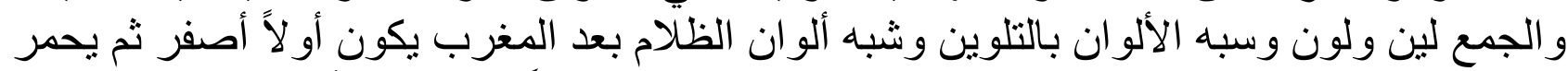
ثم يسود بتلوين البسر يصفر ويحمر ويسود. ولون البسر تلويناً إذ بدا فيه أثر النضجن" (حسن، (128: 2018

وقد ذهب أبو عبيدة - و هو أحد علماء اللغة ـ أن للون ثلاثة تعريفات منها النقبة و البوص و النجر.

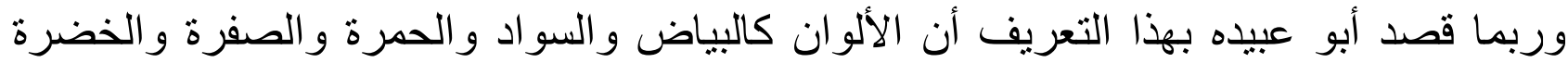

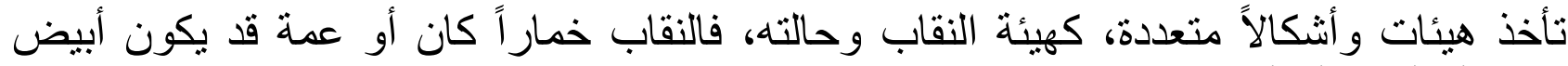

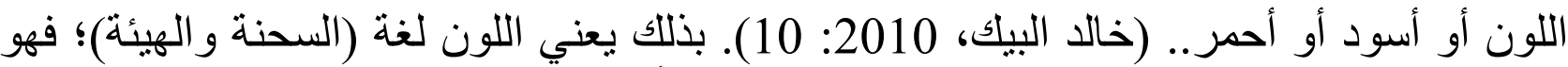

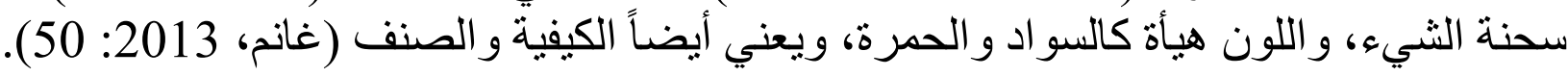

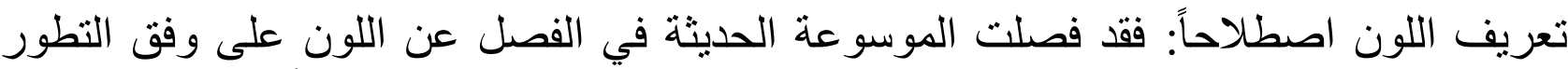

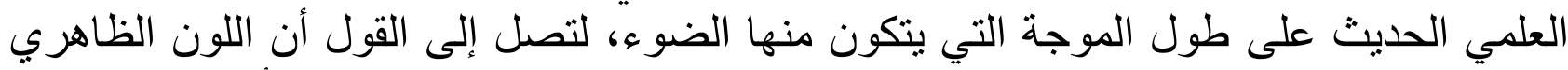

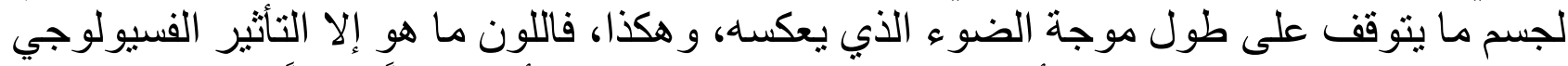

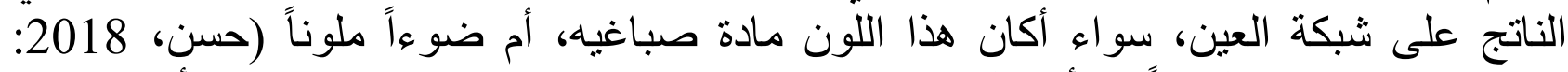

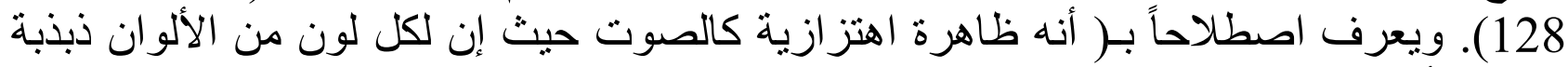

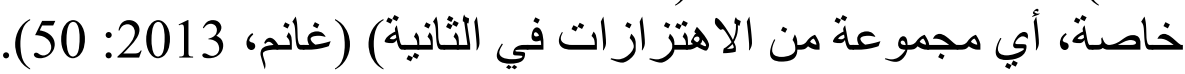

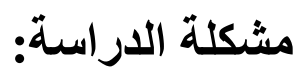
من خلال البحث والتنقيب بين جنبات الثُعر العُماني، وجد الباحث الكثير من الإشارات للألوان، 


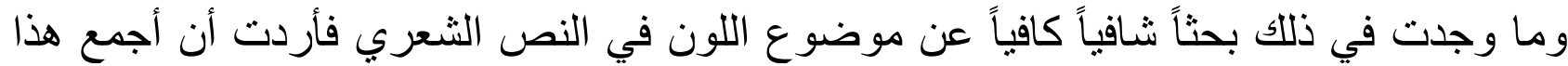

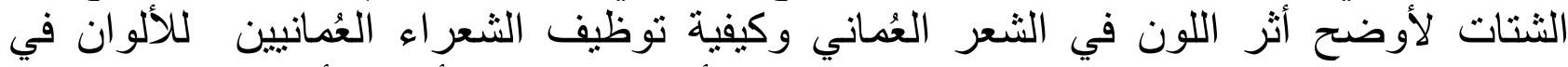

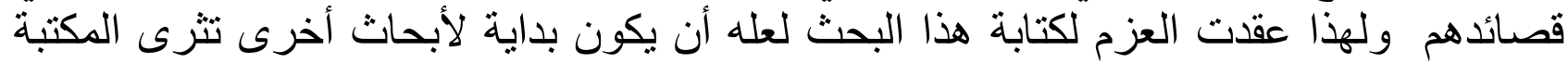
العربية عامة و المكتبة العُمانية خاصة.

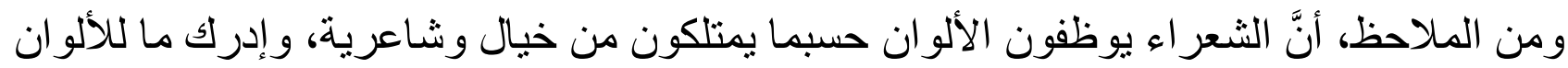

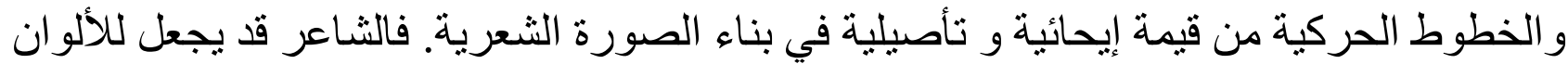

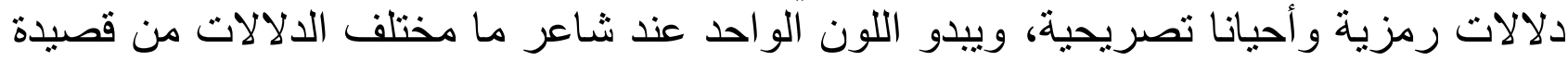

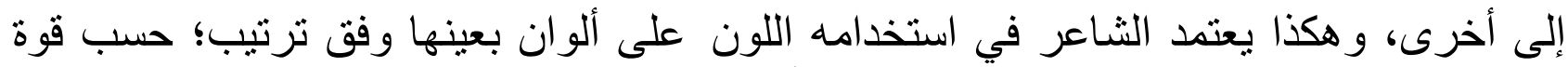

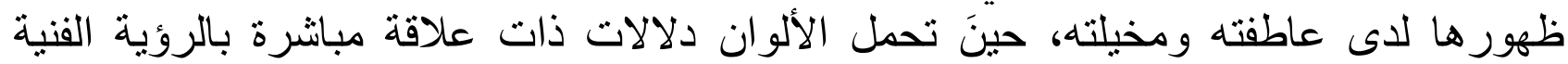

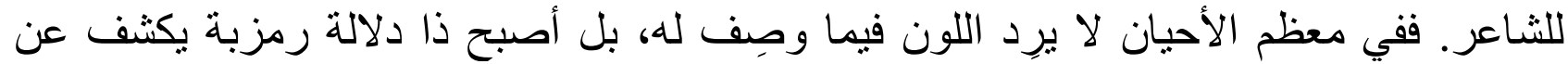

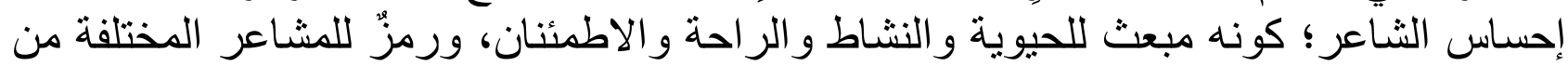

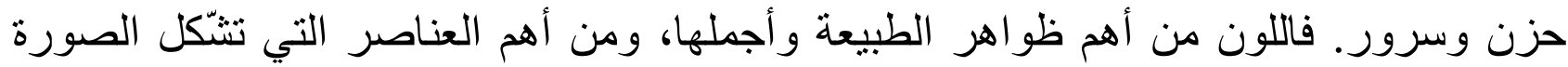
الفنية، لما يشتمل عليه من الدلالات الفنية و النفسية و الاجتماعية والرية الرمزية.

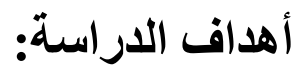

أ. عرض لمحة وتأصيل اللون فى الثعر العربي قديما وحديثا. ب. تتبع درجات الألوان وصفاتها. ت. مناقتة وتحليل مدلو لات استخدام الألوان في الشعر العُماني.

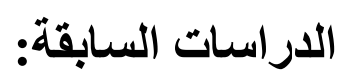
دراسة زادة، عيسى متقي (2014): دلالة الألوان في شعر المتنبى، ذكر فيه أنَّ الأبحاث دلت

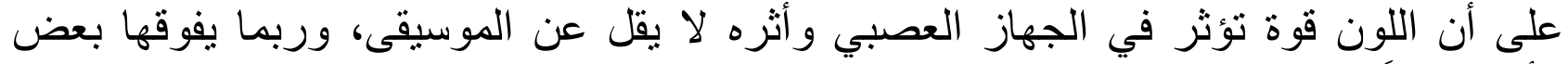

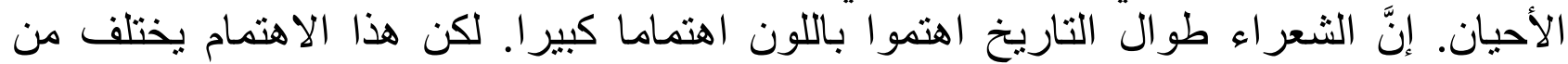

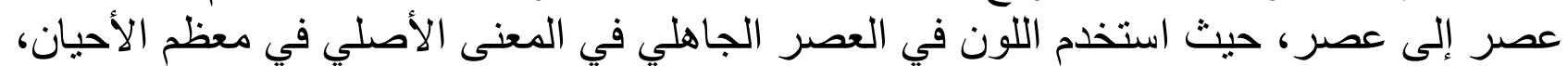

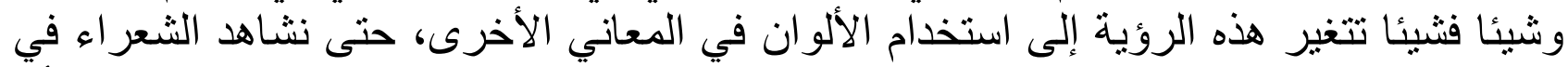

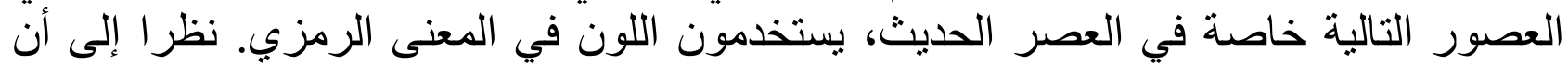

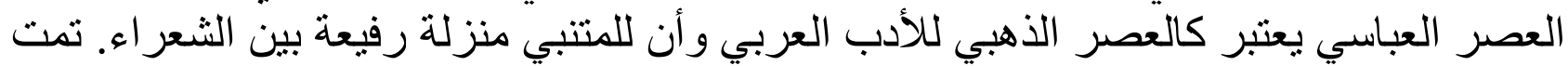

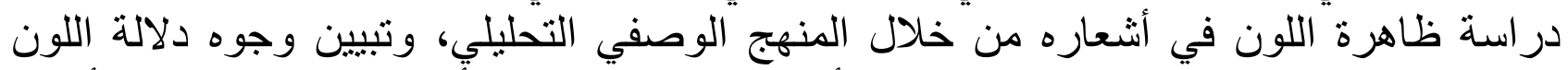

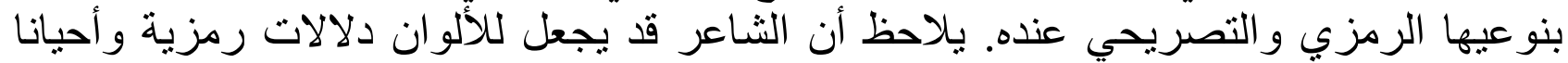
تصريحية، وقد يستخدم هذين النوعين في بيت و واحد.

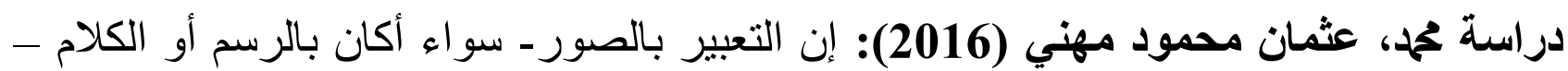

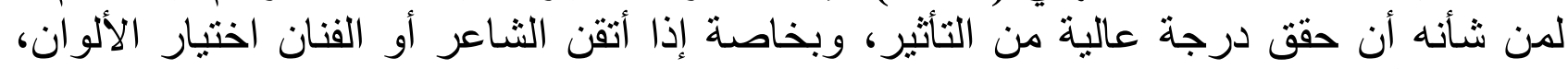

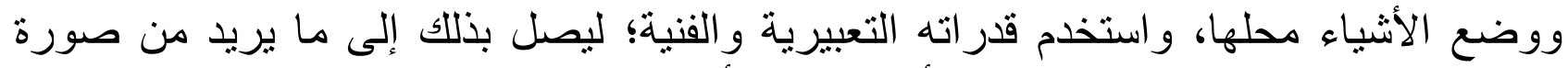

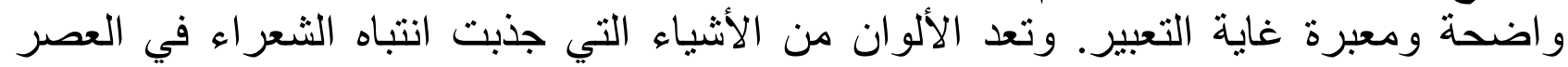

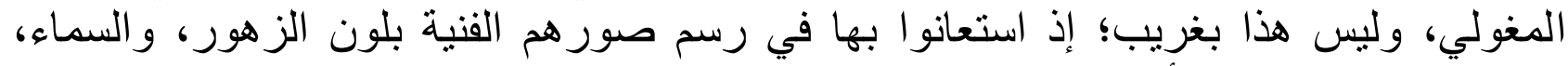

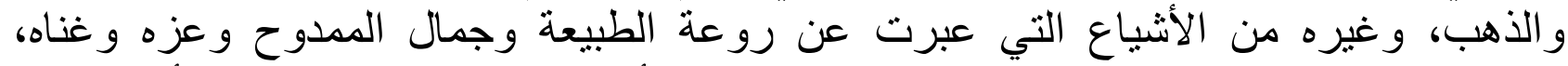
وخز ائنه المملوءة بالذهب والجو الأهر الهي كما ارتبطت هذه الألوان بموجودات في الكون، أو بآية من وني 
آيات الله عز وجل فيه، منثل: زرقة السماء، وظلمة الليل، وبياض النهار وذهبية الثمس و غير ذللك.

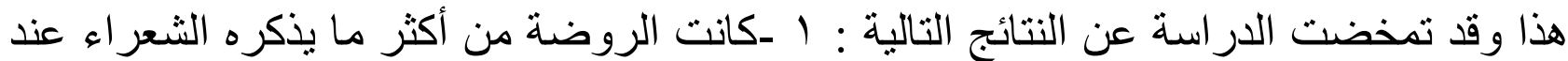

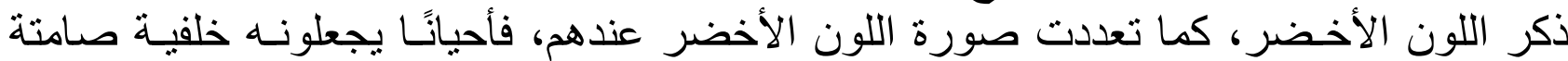

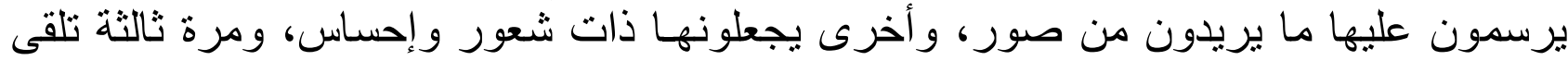

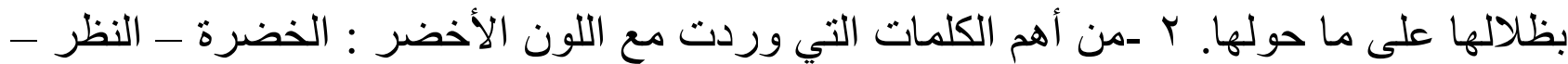

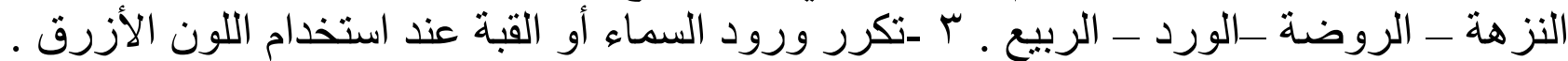

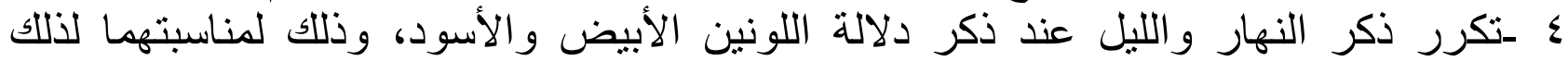

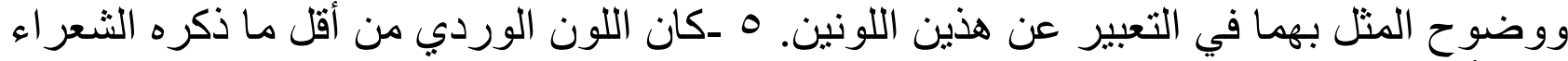
من الألوان في قصائدهم .

دراسة حسن، خالد صكبان (2018): تناول البحث بالدر اسة و التحليل دلالات استعمال اللون في الثعر العربي القديم. (الثعر الجاهلي انموذجا) وقد جاءت هذه الدراسة للكثف عن الدالالات التي

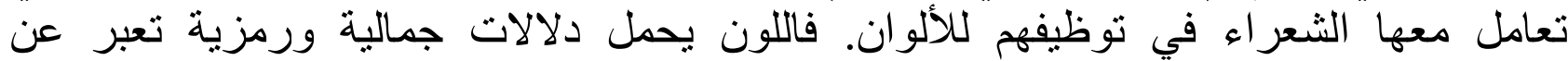
موضوعات الحياة، وحاولت الدراسة أن ترصد انفعالات الثاعر العربي القديم بها من خلاءلاتل التمثيل بنماذج شعرية تكشف لنا رؤية الثاعر العربي القديم للألوان ودلالاتها النفسية و الاجتماعية، ومدى تأثير التقاليد والموروث الثقافي في فهم الثناعر لهذه الدلالات، ذلك الفهم الذي

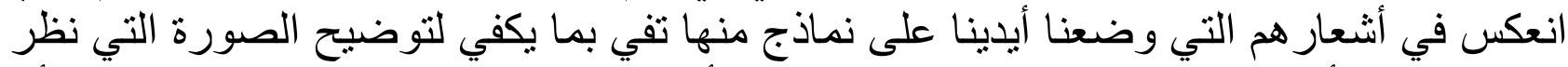

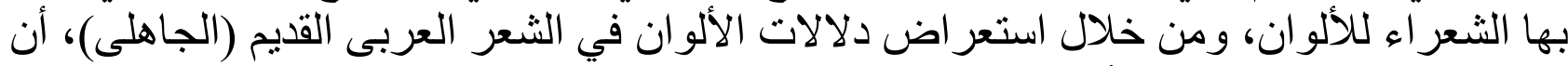

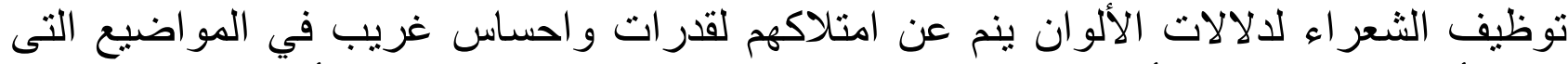
يمكن أن تستخدم فيها، الأمر الذى بدلل على ادر اكهم الحسى لخاصية هذه الألوان، الأن وفهم عميق للالالات التى تحملها في خطوطها الباهنة او العميقة، فقد كان الثاعر الجاهلى مبدعا في تشكيل الصور الحسية البصريةة، وتمكن من الوصول الى غرضي غروله بقدرة كبيرة وبصيرة نافذة و عاطفة صادقة، أكدت أن اللون كان عنصرا من العناصر التشكيلية العضوية في العمل الفنى ذو وظيفة التهنة

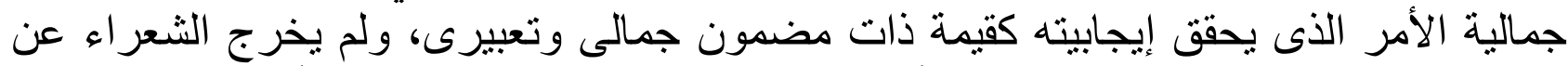

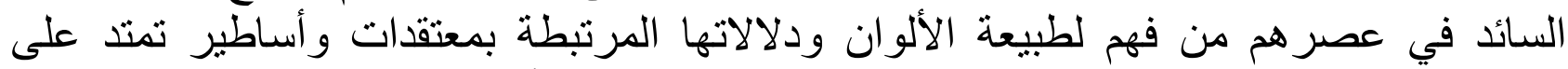

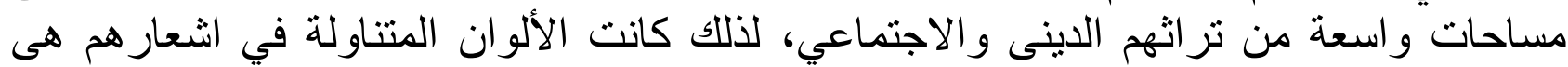

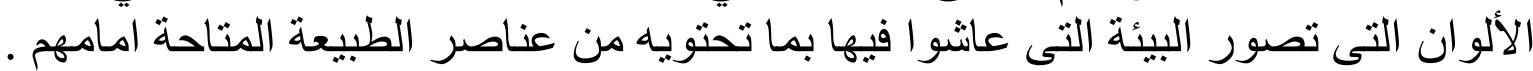
دراسة القرعان، فايز عارف سليمان (2008): تناولت الدراسة ظاهرة الألوان ودورها البلاغي في إنتاج الدلالة في الخطاب الثعري الحديث، منخذة شعر حيدر محمود نموذجاً. وقد انطلقت في تناولها من المنطقة الأسلوبية للصياغة الثعرية التي ظهرت فيها مروراً بالحقول الموضو عية التي

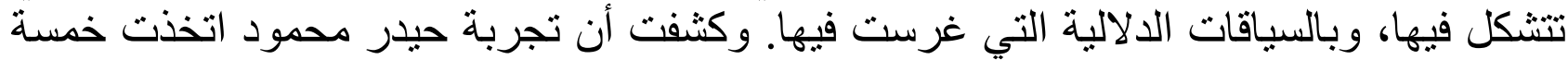

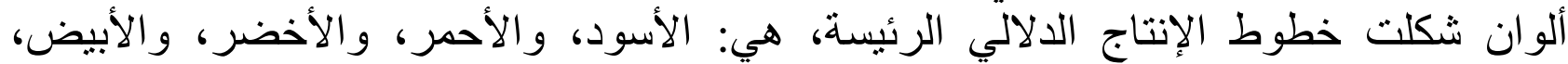

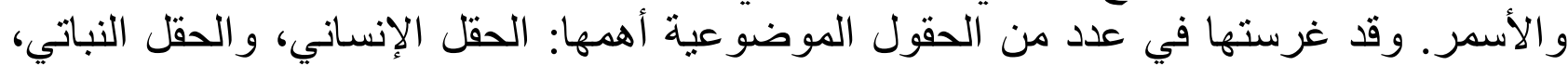
وحقل الطبيعة، وحقل المعنويات. ووجدت أنها تعاملت مع الدلالات التي تتتجها الألوان من خلان الآل محاولة المزج بين دلالات الخارج (ثقافة المو اضعة) ودلالات السياقات الداخلية حيناً، ودن خلت خلاتل

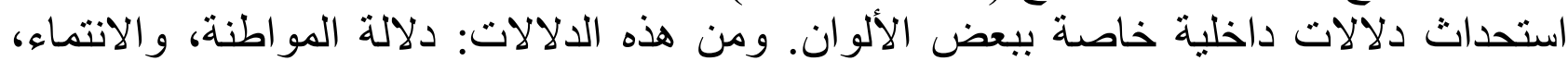
و الكبرياء، و الفرح، و الأمل، و التفاؤل، الحياة، و العطاء. 
منهج الدراسة: اعتمد الباحث المنهج الوصفي التحليلي، من خلال جمع المعلومات من المصادر و الوثائق و مناقثتنها علميًا.

\section{المبحث الأول: لمحة وتتأصيل اللون في الشعر العربي}

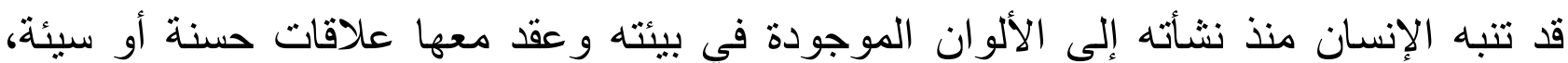

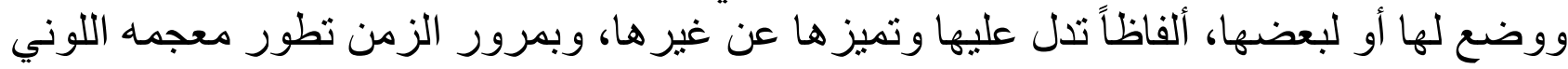

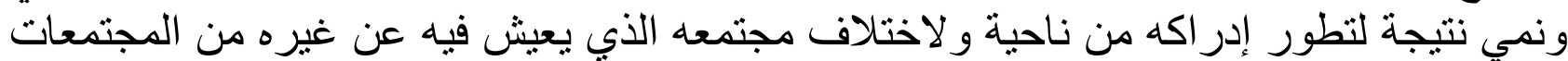

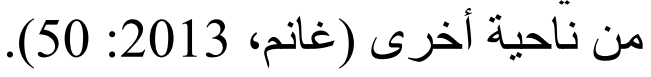

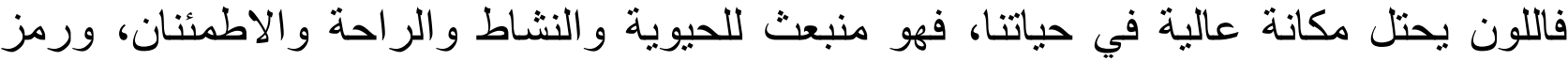
لمشاعرنا المختلفة، وان دلالاتها في العربية عميقة الجذور، تواكبة التب الحياة العربية في بيئاتها

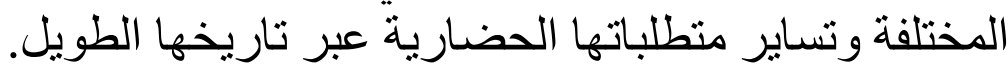

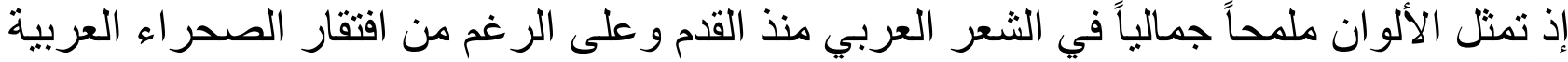

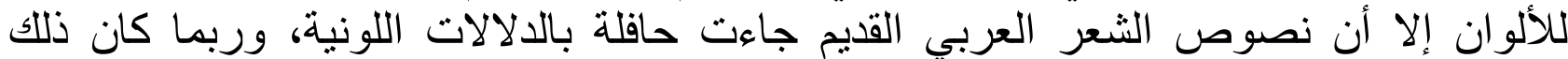

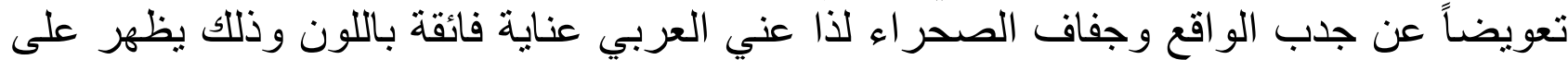
ألسنة شعر اء العربية وخطبائها واشتندت العناية في عصور ازدهار اللغة العربية (غانم، 2013:

\section{كيف بدأت معرفة الإنسان للون؟}

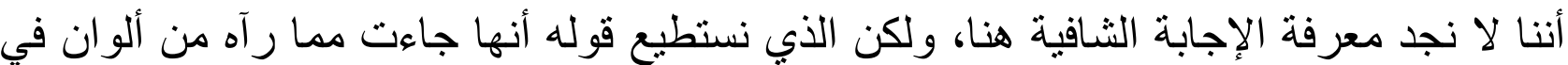

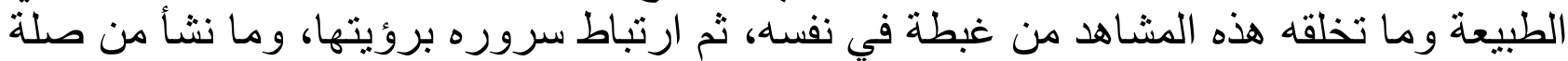

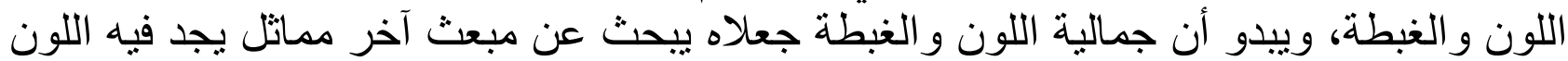
ثم يوظفه إكساباً ( لأشيائه ) جمالية أو اكتساباً للغبطة (شاع الإنة الدين، 1999: 27).

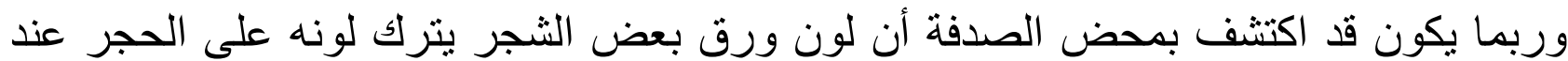

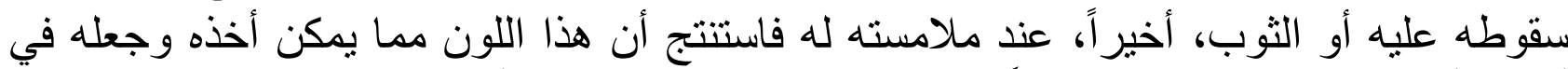

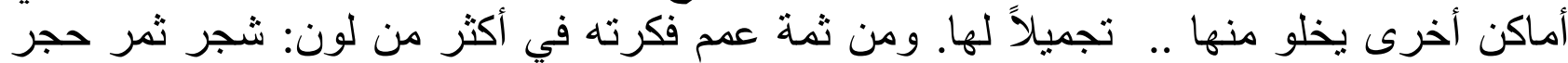

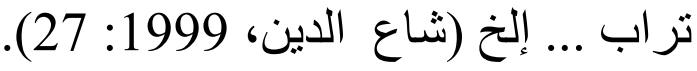

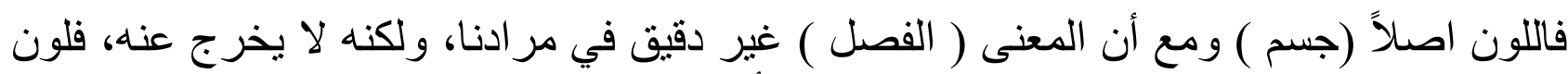

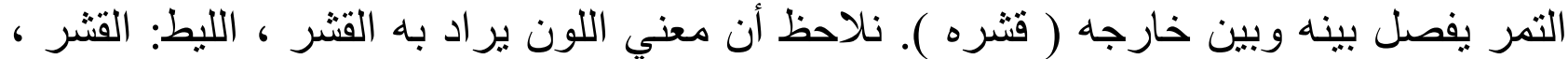

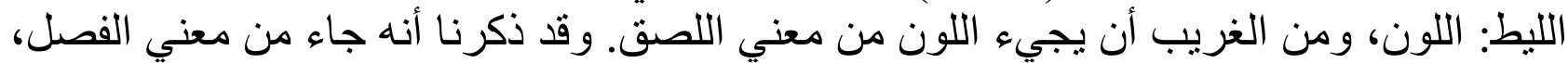
وهو معني اللصق يناسب قولنا، إن اللون كان جسماً. ونجد هذا في في معني آخر : الليط: كل شيء كانت لله صلابه ومنانة (شاع الدين، 1999: 28).

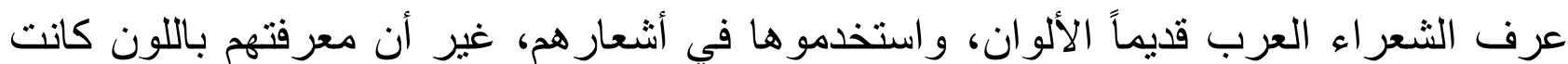

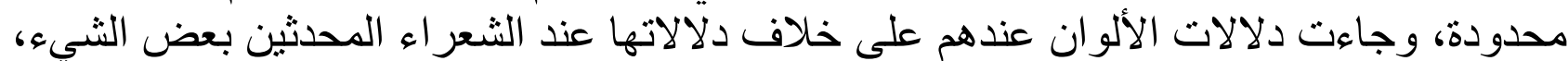

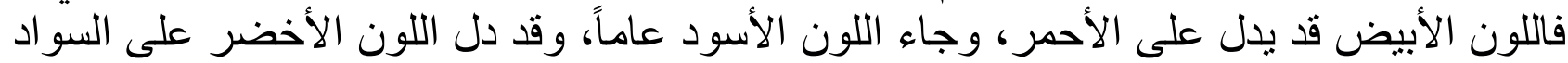

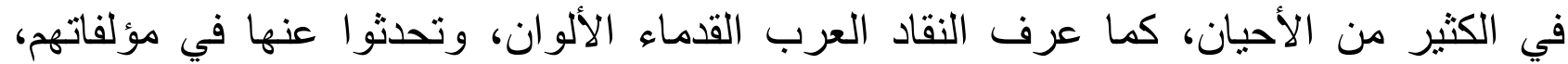

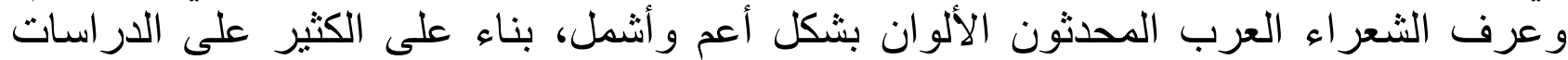


العلمية الحديثة للألوان لدي الغرب (الغز الي، 2006: 400).

الألوان عند القدماء:

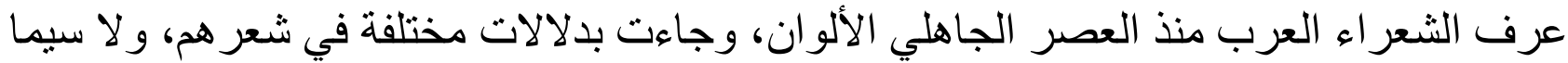

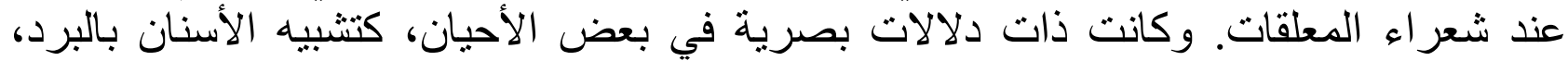

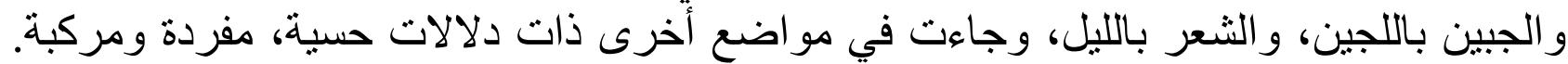

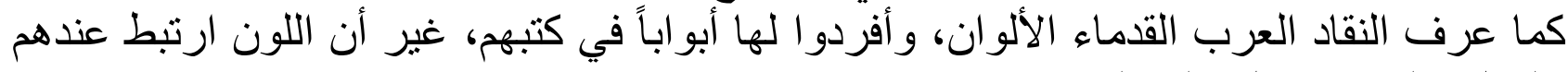

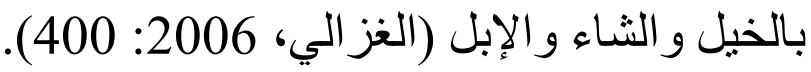

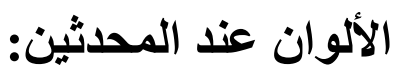

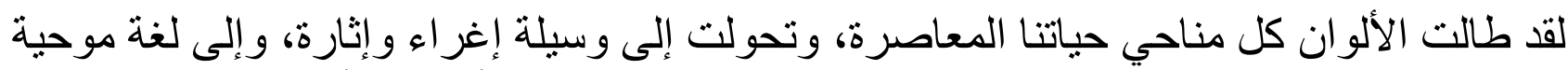

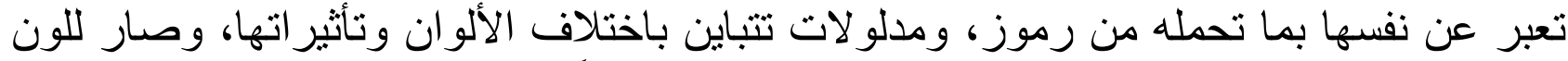

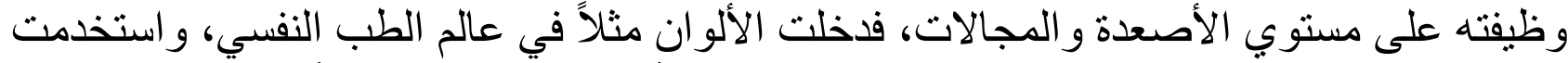

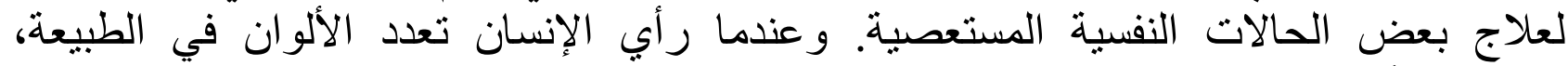

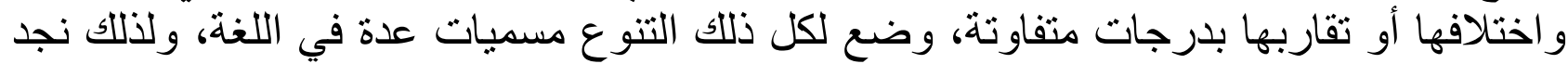

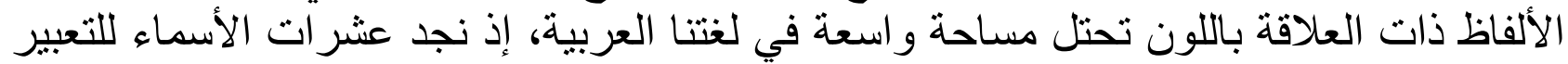

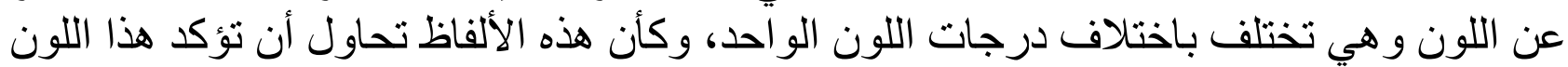

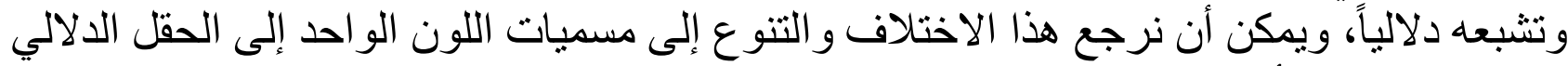

الذي ير اد فيه، فالأبيض في الإنسان قد يختلف عن الإن الإبض فيض في الحيو ان (حسن، 2018: 128).

\section{دلالة اللون فى الثعر العربي}

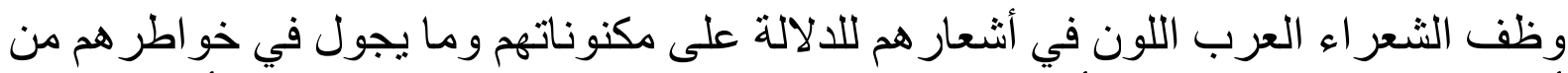

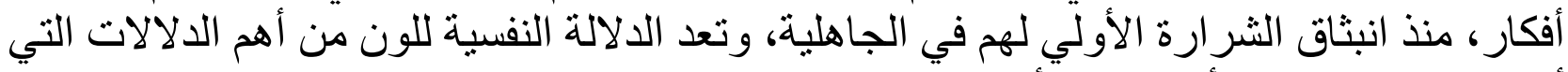
أستعملها الشعر اء في أشعار هم و أكثر ها: الثنا.

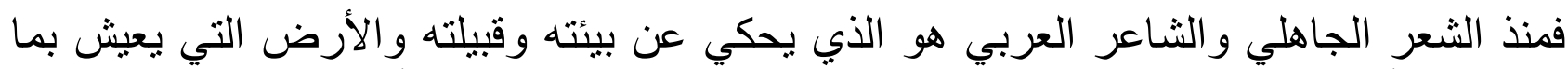

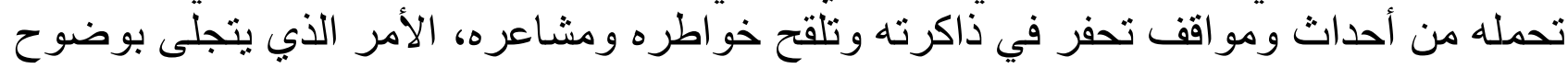
في قصائدهم التي تتغني بالبيئة، تللك القصائد التي نحس فئ معها بطبيعة الثـاعر ومجتمعاه(حسن، (129:2018

ولكل لون من هذه الألو ان دلالتها الخاصة عند الثناعر الذي تسعفه مو هبته أن يتذوق معني الألوان

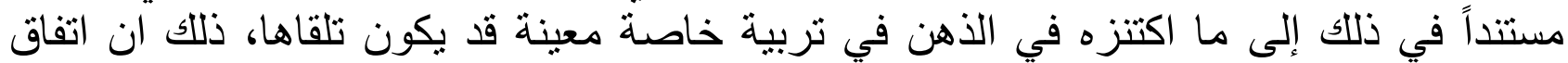

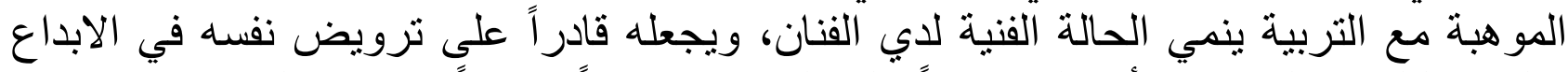

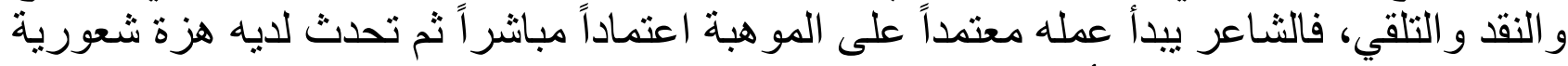

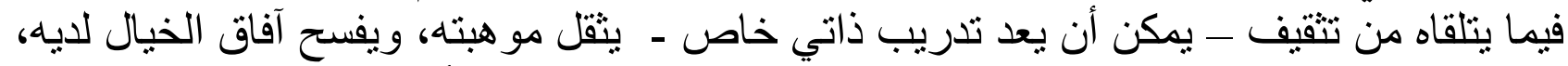

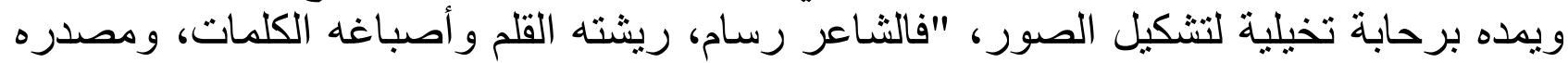

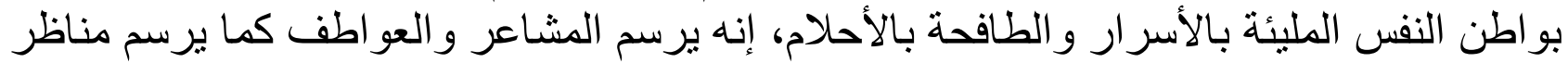

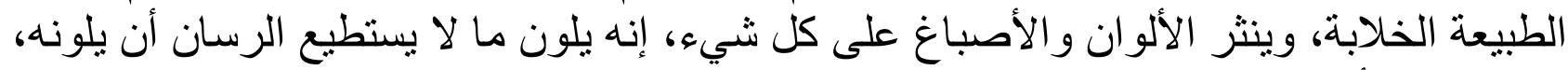

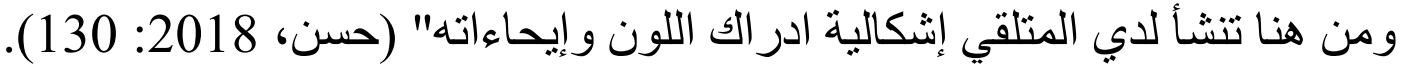


وقد تميز الثعر اء العُمانيين في توظيف الألوان في أشعار هم ، ومن أمثلة ذلك نري قول الخليلي في قصيدته "في الخميلة":

وخميلة حاك الربيع بساطها خضر ا ونمنمها بز هر كاس

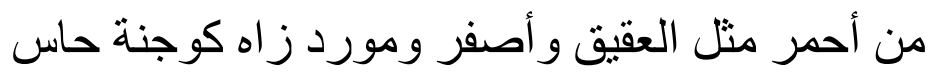

الألوان الاساسية والفرعية (الثانوية):

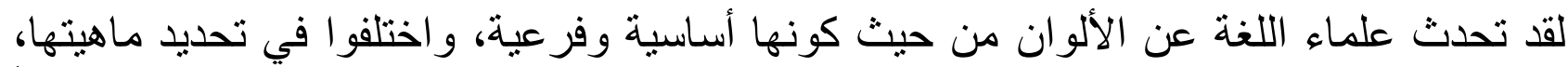

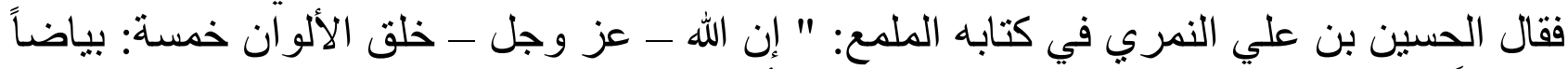

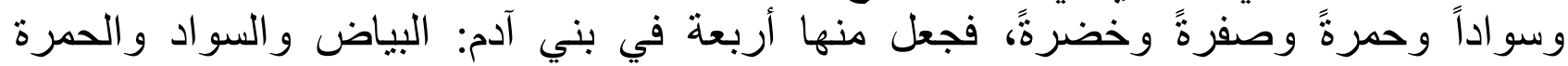

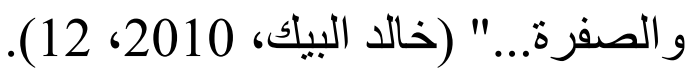

كذللك أوضح رأيه في أصل الألوان الفرعية فقال: " فإن قائل: أين الغبرة والسمرة والزئ والزرقة

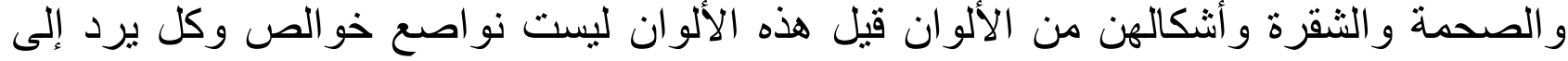

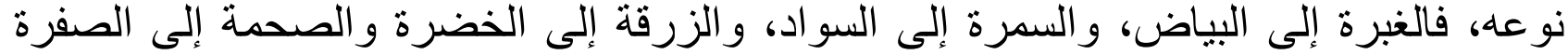

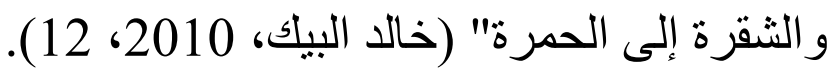

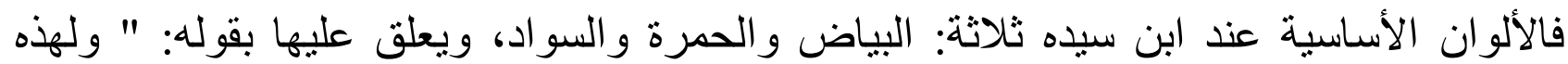

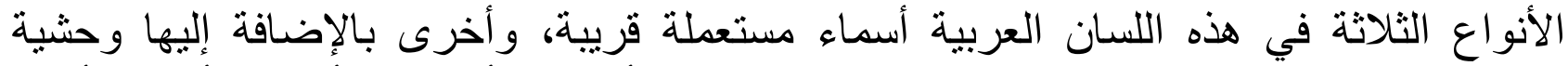

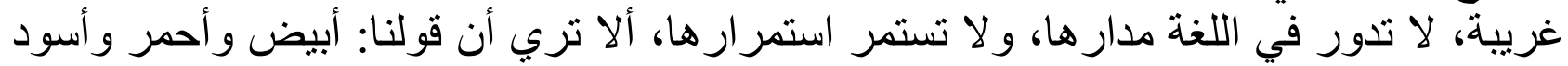

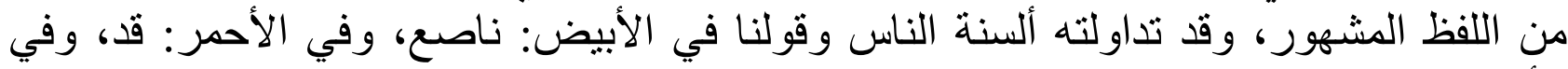

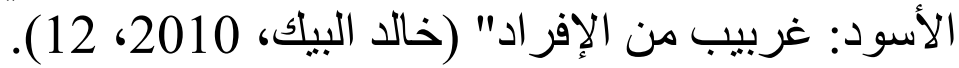

المبحث الثاني: الألوان درجاتها وصنات الأنها

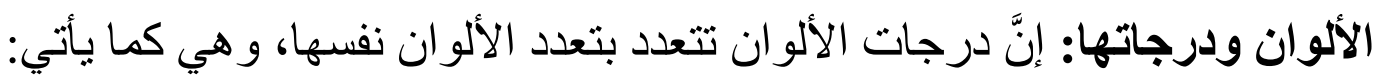

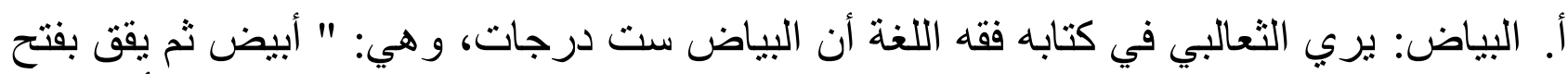

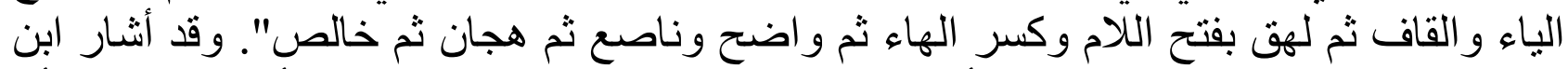

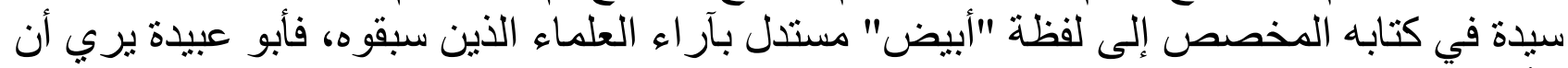
الأبيض قهد، و القهد النقي اللون.

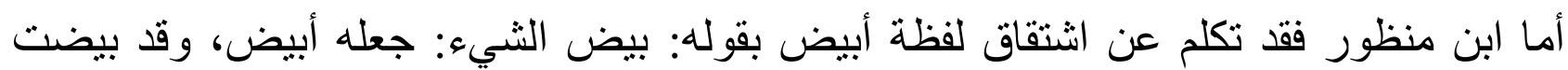

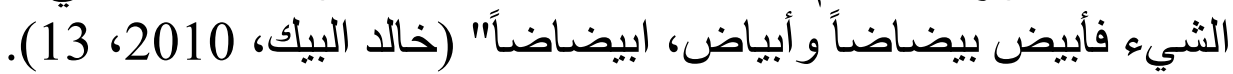

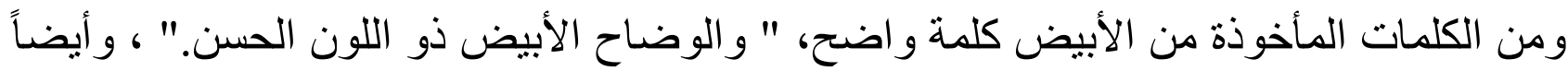

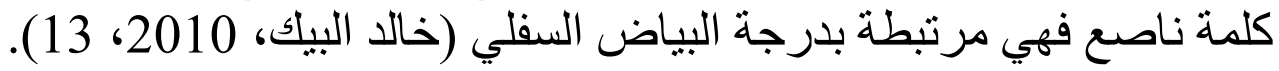

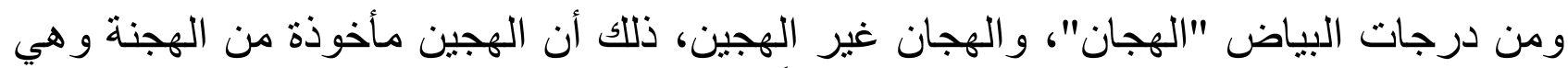

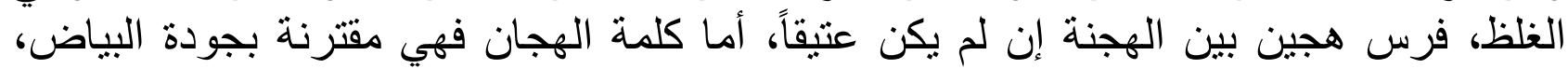

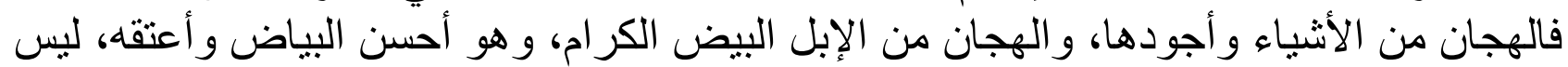
في الإبل فحسب و إنما في الرجال و النهاء والنهاء أيضاً (خالد البيك، 2010، 14). ب. السواد: يصف أبو عبد الله النمري السواد إلى درجات كثيرة منها: أسود وهو أقل درجات 
السو اد، ويليه الحلكوك، و الفاحم، و المسحنك، وحلبوب، و وغربيب و هكذا. أما السواد عند الثعالبي

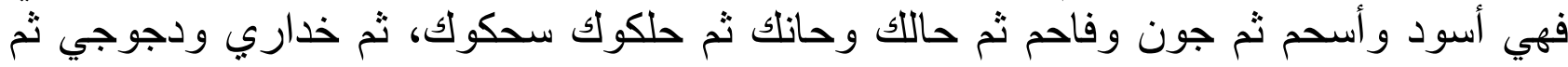
غريب و عذافي.

وقد أثنار ابن سيدة إلى درجات السواد علق على بعضها، فمثناً تعرض إلى كلمة حلكوك و اشتقاقها

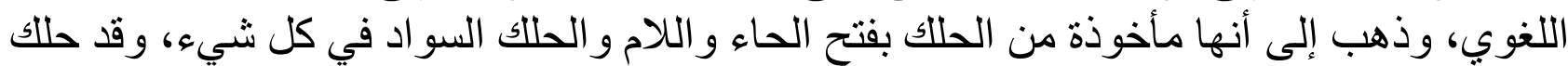

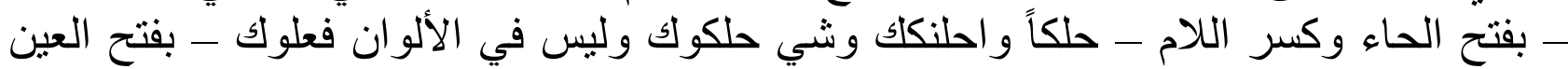

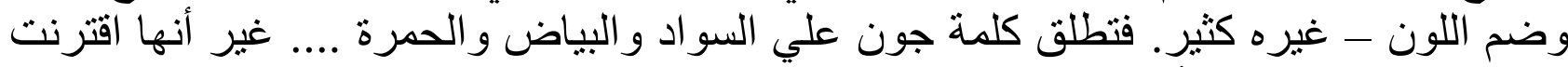
فيما بعد بالدكنة ولم يقل أن الجون بمعني الحمرة سوي ابن دريد (خالد البيك، 2010، 15).

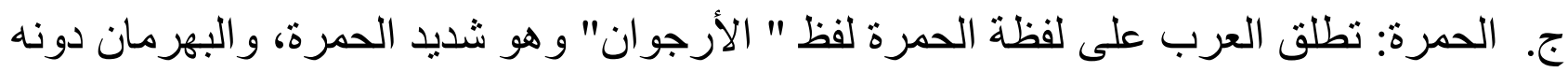

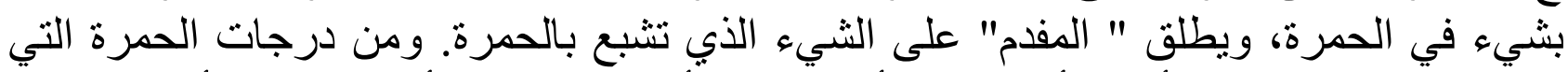

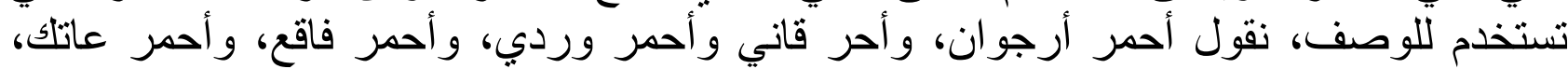

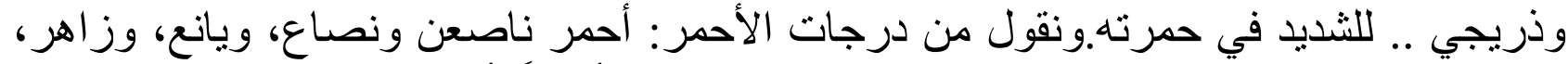

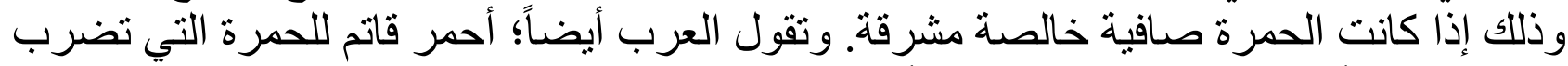
إلى السو اد، و أحمر فاقع للخالص الحمرة أو شديدها (خالد البيك، البكة 2010، 16).

الألوان وصفاتها

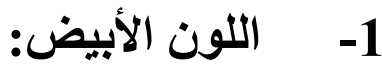

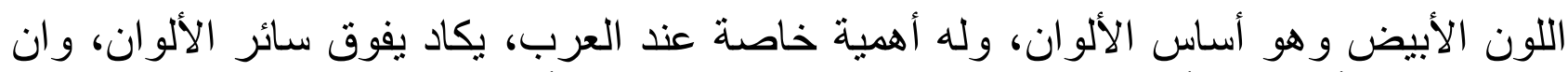

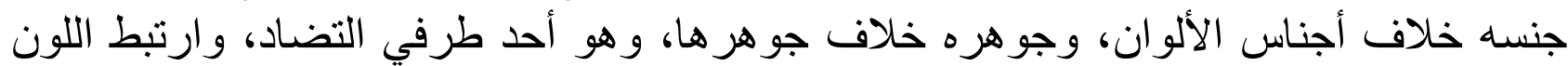

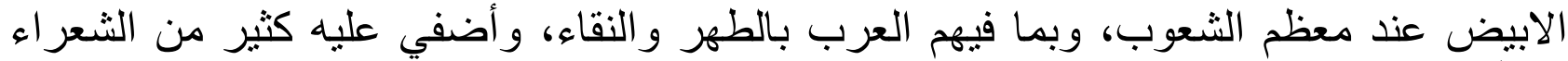

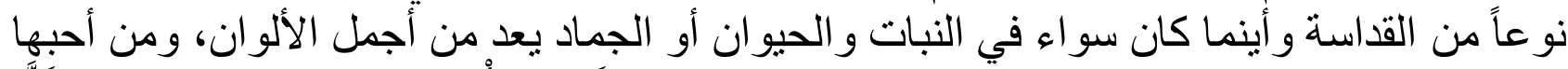

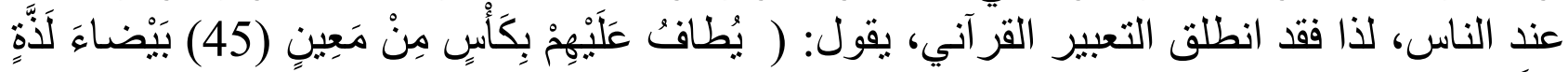

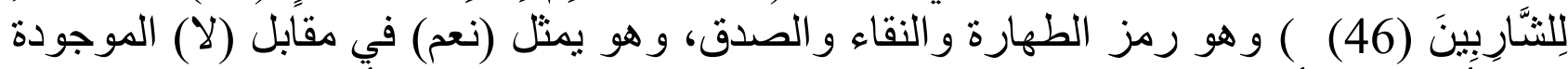

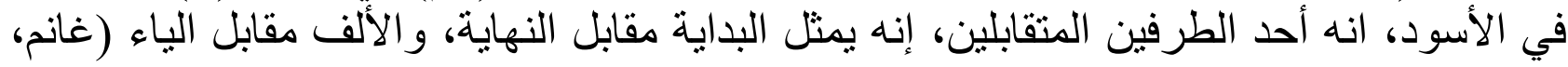

. 2013:

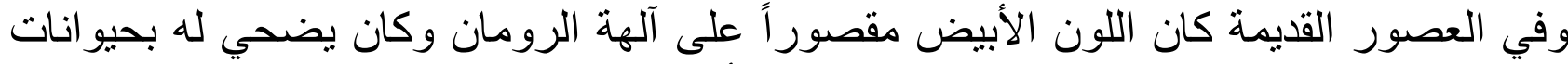

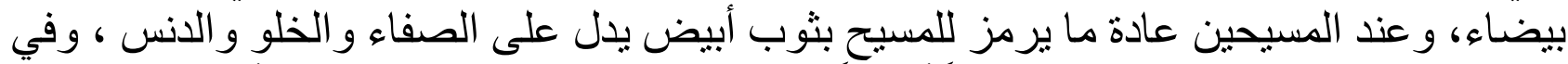

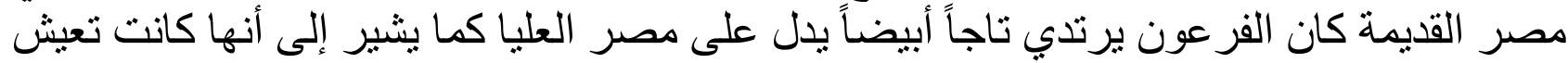

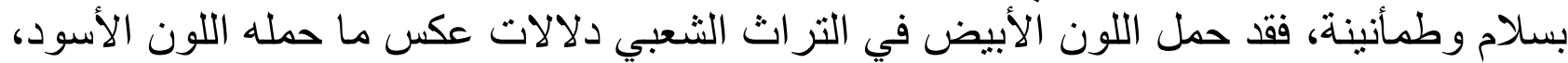

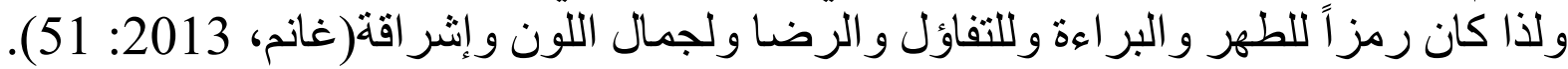
ومن استخدام اللون الأبيض في الثعر العُماني قول الخليلي في قصيدته "قابيلان" وهي قصيدة في

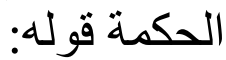

إن النهى صدقتني الر أى قائلة إن المنى دونها بيض ومران

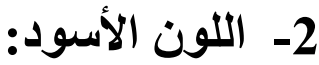
السو اد نقيض البياض، وهو رمز الحزن والألم والموت، كما أنه رمز الخوف من المجهول والميل 
إلى التكتم، ولكونه سلب للون بدل على العدمية والفناء، وهو لون التون مكروه منذ القدم، وقد رمز

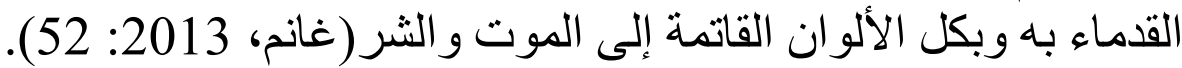

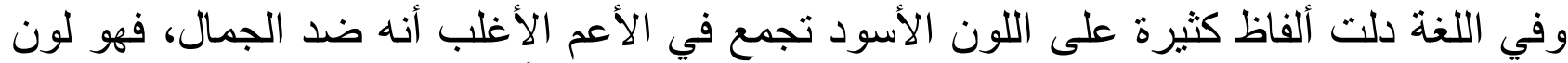

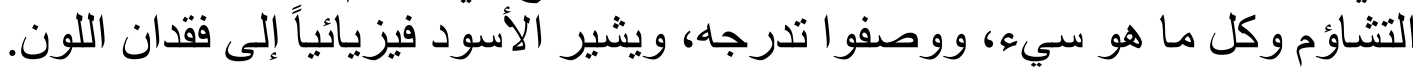

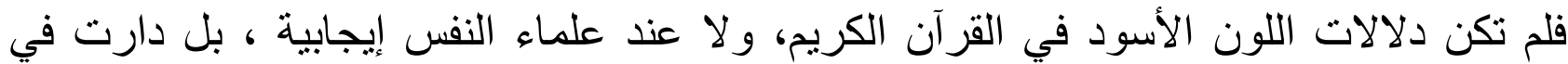

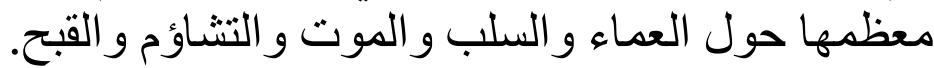

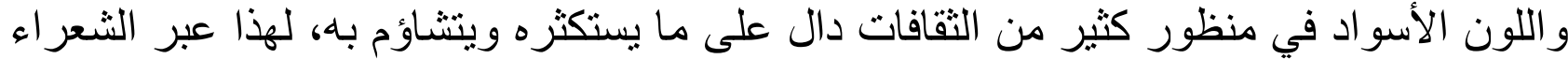

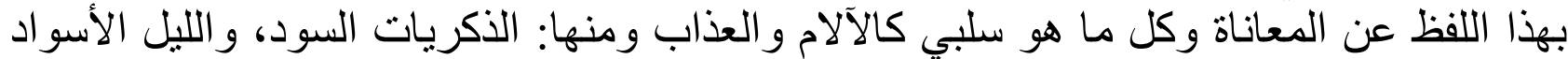

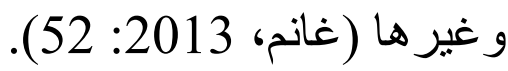

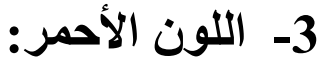

وهو أول لون عرفه الإنسان بالمعنى العلمي لكلمة اللون، إذ إن الأبيض والأسود ليسا لونيين

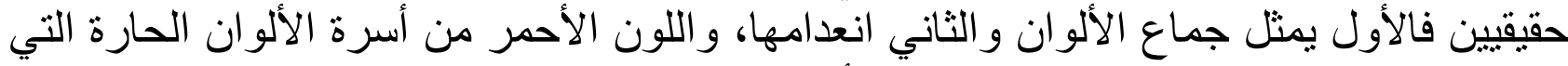

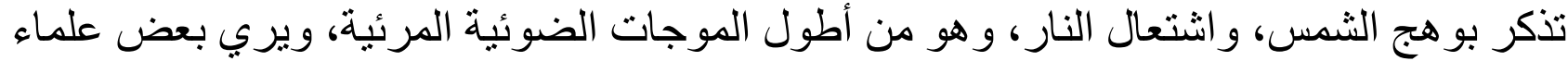

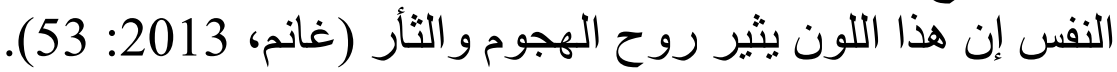

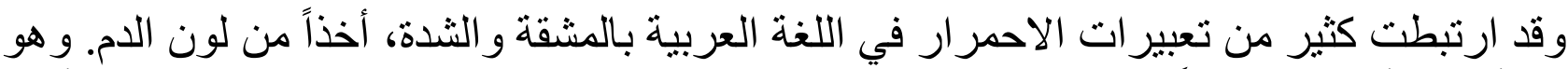

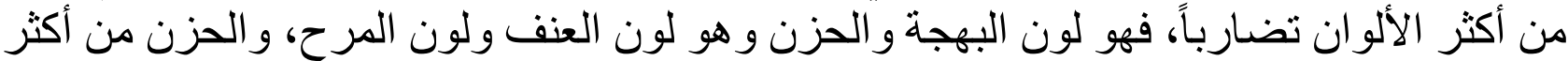

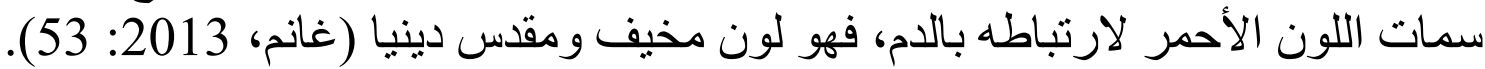

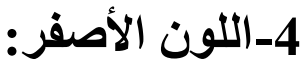

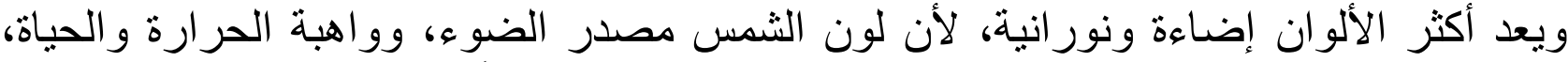

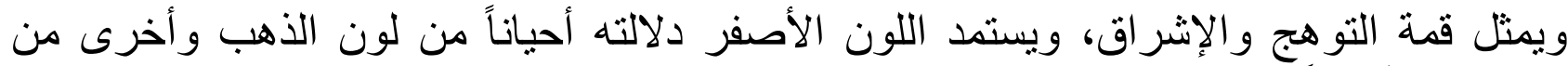

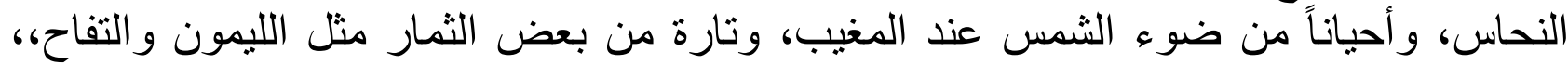

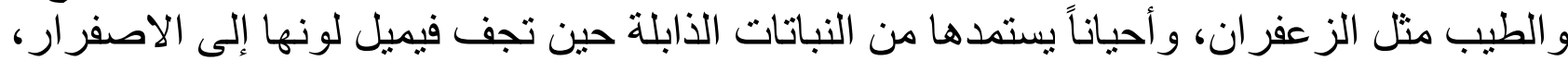

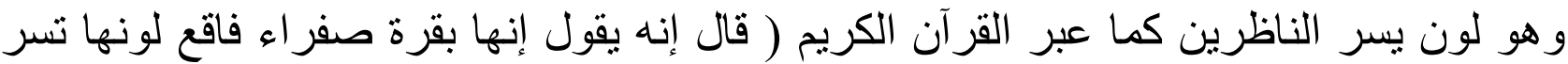

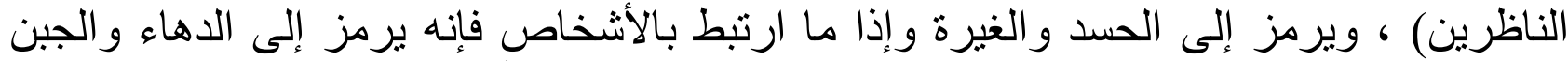

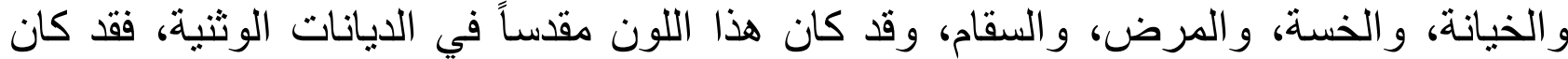

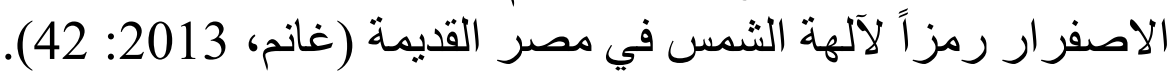

المبحث الثالث: الألوان ودلالتها المجازية الاهية

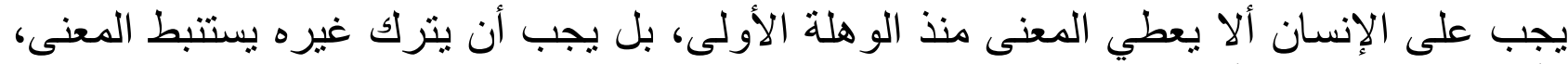

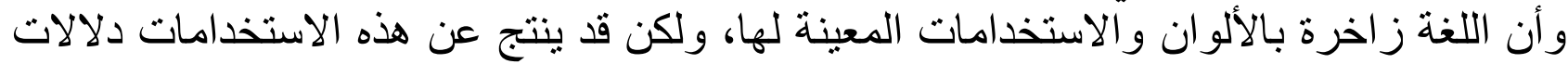
مجازية أخرى يتم استشفافها من المعنى. دلالة اللون الأخضر

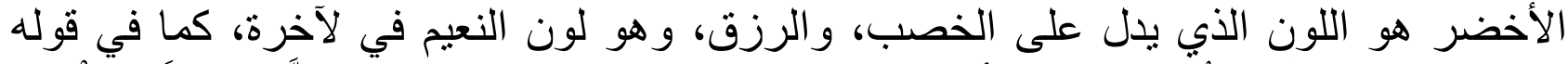

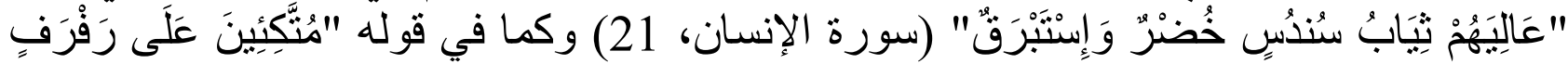




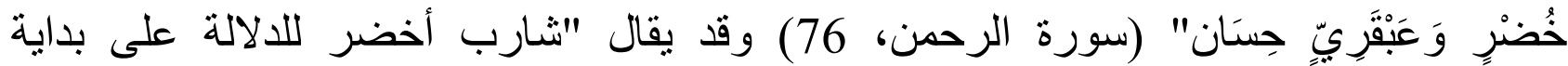

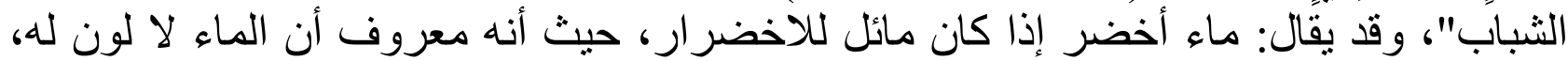

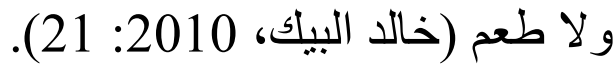

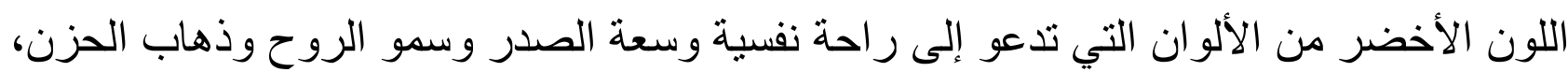

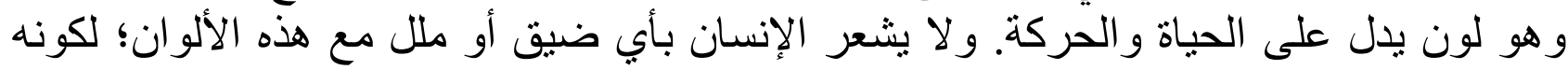

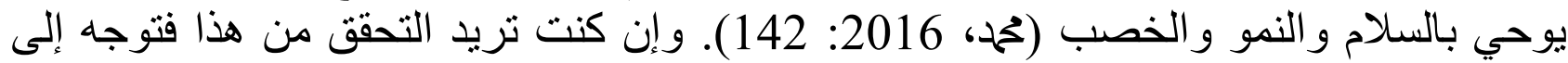

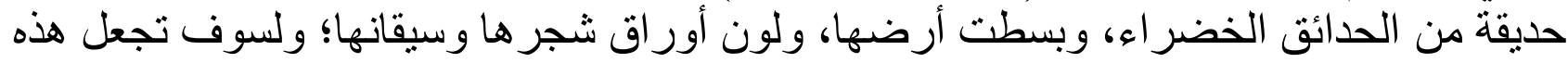

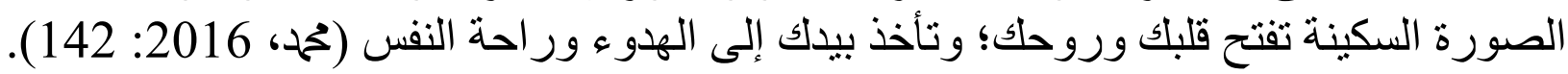

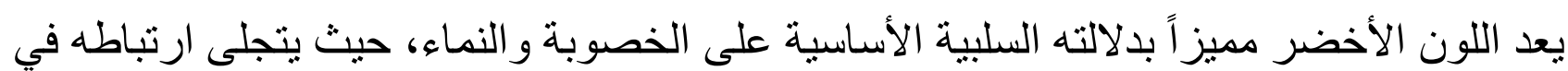

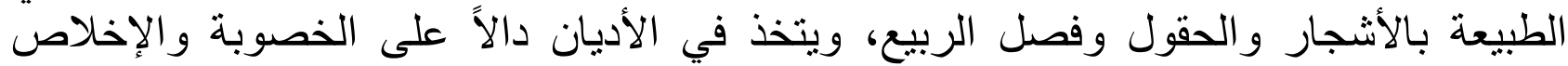

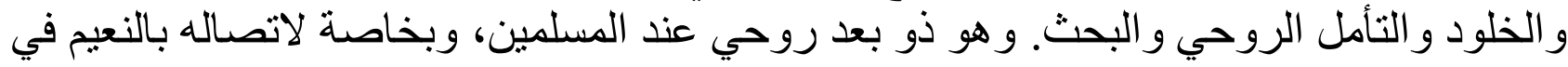

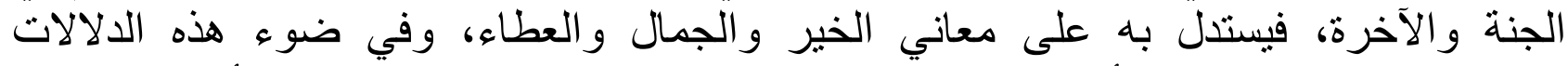

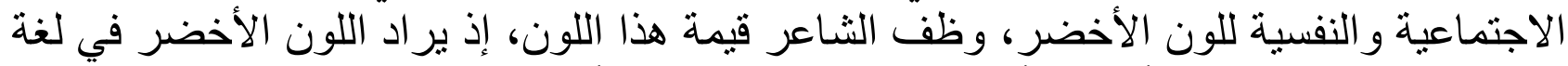

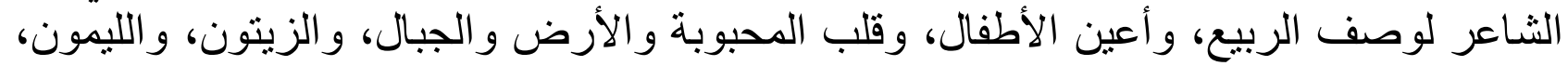

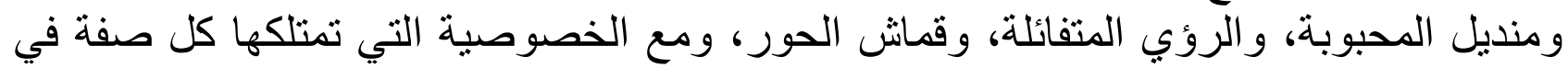

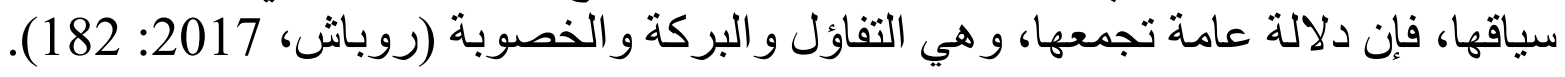
ومن أمثلة اللون الأخضر في الثُعر العُماني قول الثناعر "هلال بن سعيد العُماني" في قصيدته

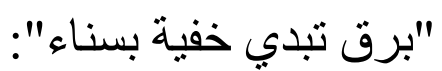

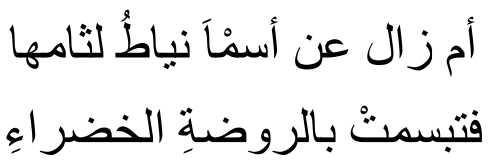

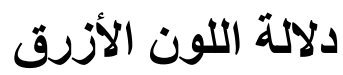

للون الأزرق ميزة تميزه عن غيره من الألو ان؛ وهي: إن هذا اللون تلون اللون به شيآن، و هما من أبرز

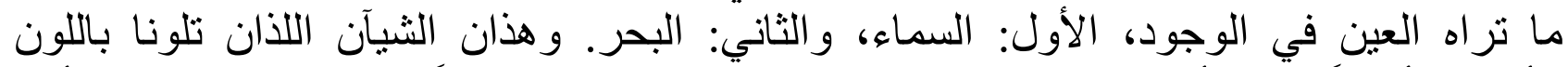

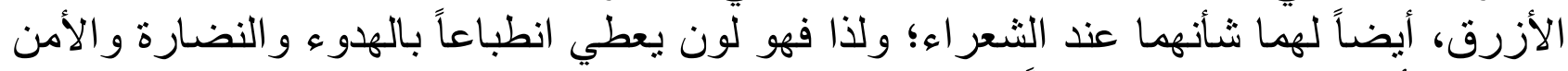

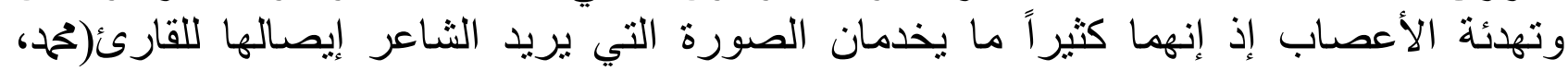
147: 2016 ومن أمثلة اللون الأزرق في الثعر العُماني قول الثـاعر "هلال بن سعيد العُماني" في قصيدته

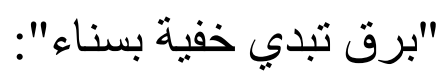

وظَنَنْتُ عُلوةَ قَ تَزَحْزَحَ سَنْفُهُها

عنها ببطنِ الخيمةِ الزرقاءٍ

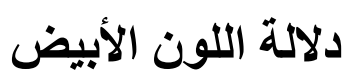

إن أول ما يطالعنا من الألوان في الثعر العربي القديم هو اللون الألون الأبيض، الذي كان سمة الجمال

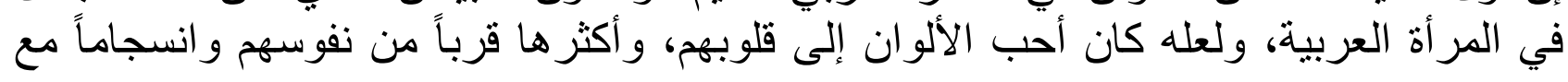


طباعهم، فكانو ايرون فيه أبهي الألوان وأنقاها، فقد كان هيام الثاعر ببياض المر أة هياماً موروثاً ،

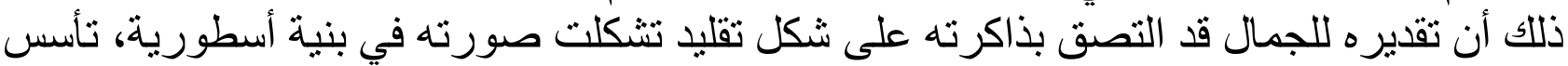

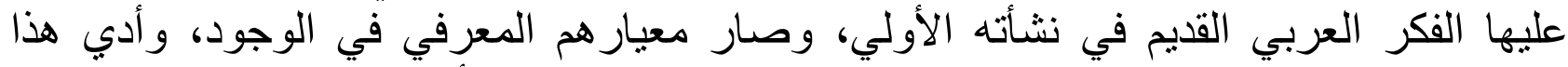

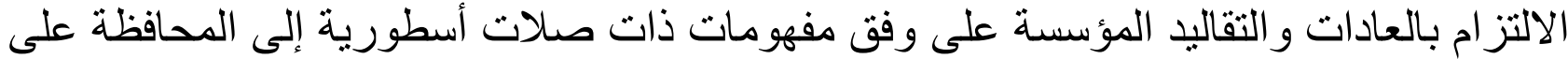

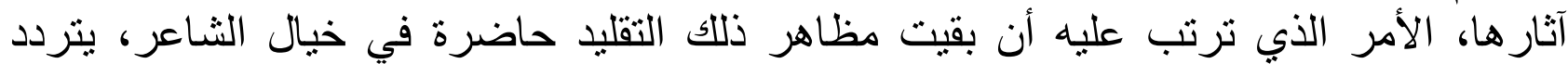
صداها في مظاهر رؤيته إلى الحياة(حسن، ألب عله 2018: 132). وإن العرب تعطي اللون الأبيض دلالات مجازية عدة منها يأتي بدلالة الإشراق والإضـاءة، وقد

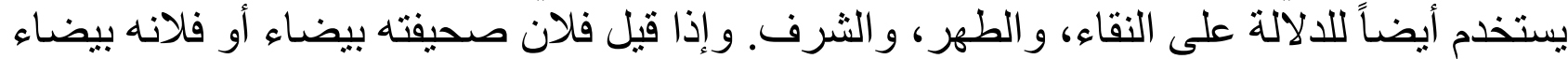

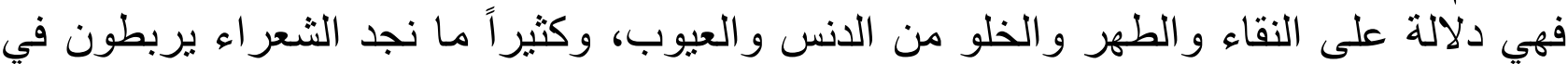
شعر هم البياض بنقاء العرض، وكما نجدهم يمدحون الأشخاص بالكرم و العفة، "ونقاء العرض من من العيوب".

فكما استخدمت العرب الأبيض للمدح، وللدلالة على نقاء العرض، أخذت الصورة المقابلة له وهي

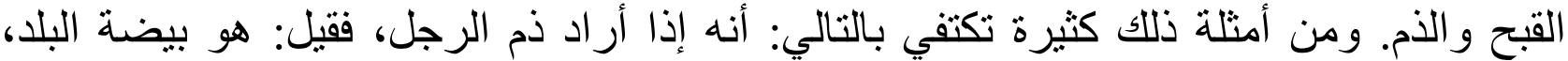
و أر ادو ا بذلك أنه هو منفرد لا ناصر لله بمنزلة بيضة، وتركها لا خير فيها ولا منفعة(خالد البيك،

فاللون الابيض من الألو ان التي تدل على الصفاء و النقاء و الأمل، و الهداية و الرشاد وحسن السريرة ورمز الطهارة وكل خير تجده في دلالة هذا اللون، حتى إن رسول الله ــلي الله عليه وسلم- حث

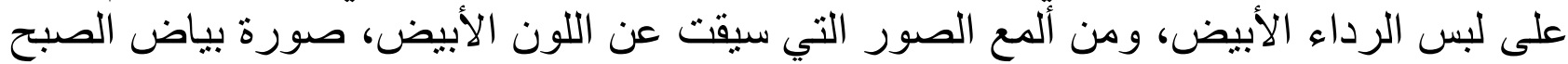
وجماله و غياب ظلمة الليل في بياضهه، وما يعني ذلك من الأمل والإقبال على الحياة(خحم، 2016:

ويدل اللون الأبيض في كثير من الثقافات على ما يستحب من المعاني، كالصفاء و النقاء و الصر احة و الوضوح، و الطهر و اللبر اعة وجمال اللون و إثر اقه، و المهادنة و المسالمة، وقد أصبح اللون مصنئ مصدر التفاؤل عند كثير من الثُو وب (روباش، 2017: 174).

\section{دلالة اللون الأصفز}

اللون الأصفر قد يكون مرغوباً تارة، وخاصة إذا اقترن بالذهب و الز عفران، وقد يكون مرفوضاً

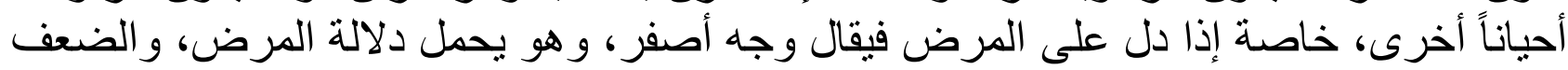

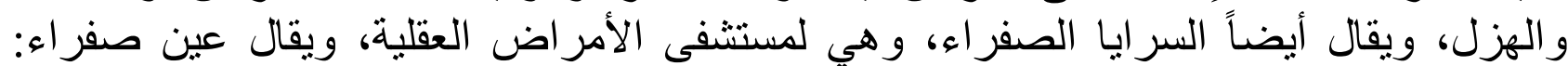
وهي دلالة على العين الحقودة الحاسدة (خالد البيك، 2010، 21 21). ومن أمثلنه في الثعر العُماني قول الثاعر جمعة الحنجري في رثاء حمد بن حميد بن عبد الله الحارثي:

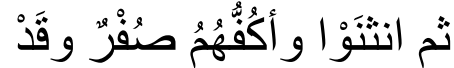

$$
\begin{aligned}
& \text { مُلِئتنْ قلوبُهُ بهِه حزنْ الأبَدْ }
\end{aligned}
$$

دلالة اللون الأحمر اللون الأحمر من الألوان ذات الدلالات المتعددة، أحياناً بدل على القرب، و أحيانا بدل على الدم 


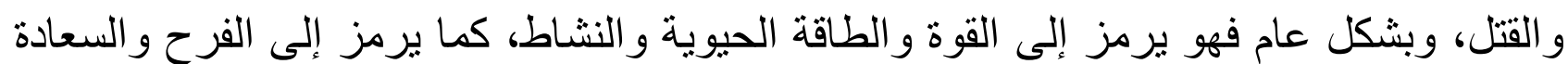

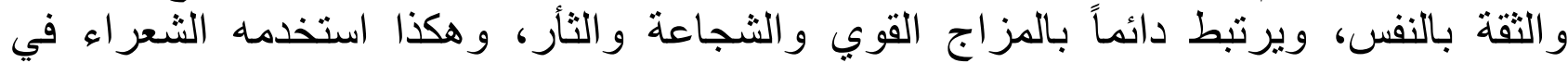

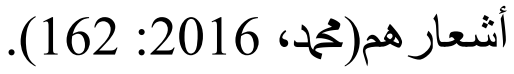

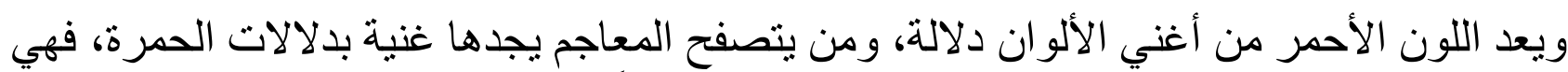

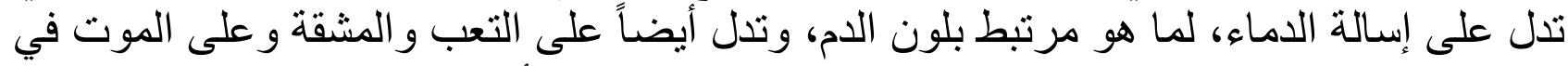

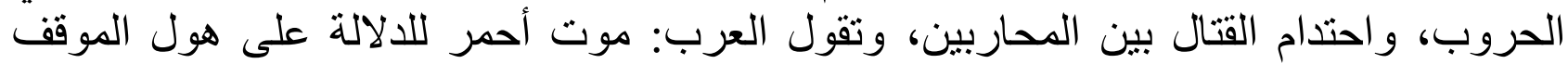
وشدته (حسن، 2018: 138)

ويقال عند اشتداد القتال أحمر البأس، وقد يقال سنة حمر اء للالالة على جدبها وفقرها، وليس اللون

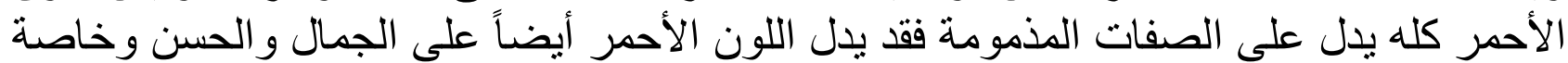

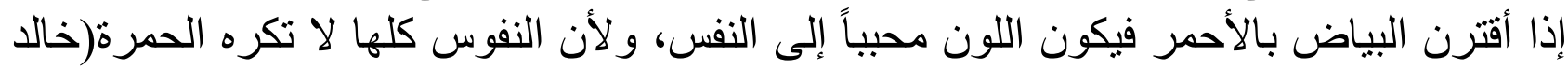

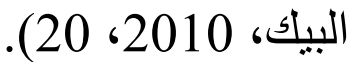

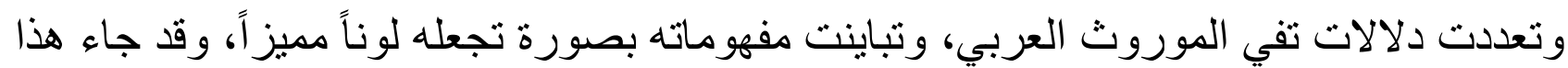

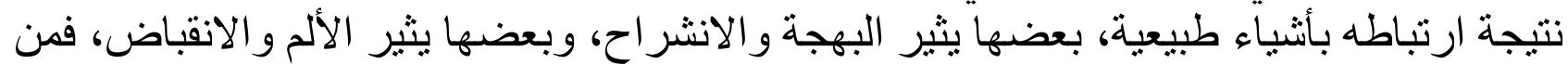

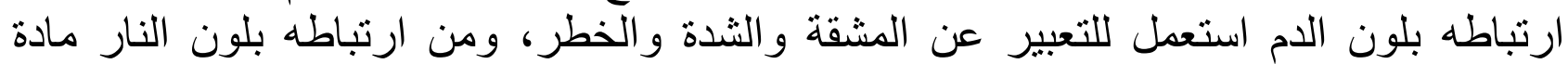

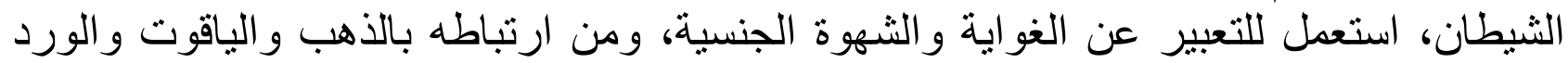

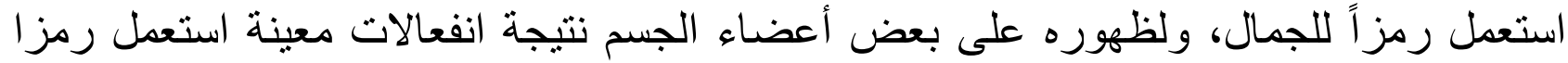
للخجل و الحياء تارة، وللغضب تارة أخرى، و غير ذللك (روباش، 2017: 182).

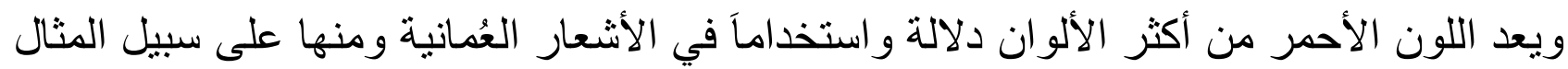
قول الثـاعر "سعيد العُماني" في قصيدته "برق الأن تبدي خفية بسناء":

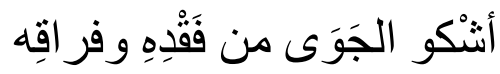

و أبكي عليه بدمعةٍ حمر ايٍ

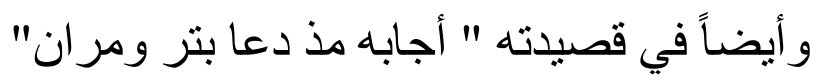

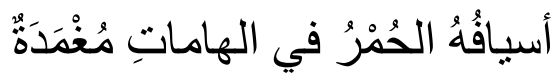

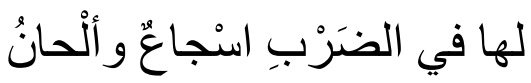

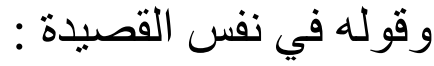

وللنجيعِ احمر ارُ في سَنَابكِها

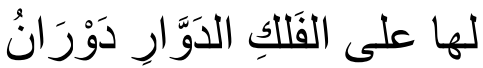

دلالة اللون الأسود

كثثرة هي دلالات اللون الأسود في شعرنا العربي القديم، وهي دلالات مأساوية في أعمها الأغلب،

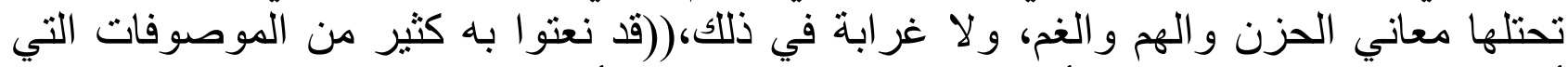

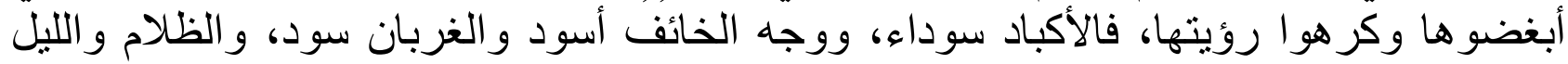




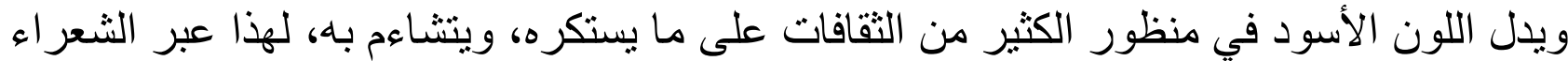

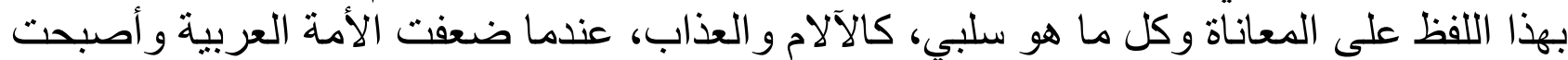

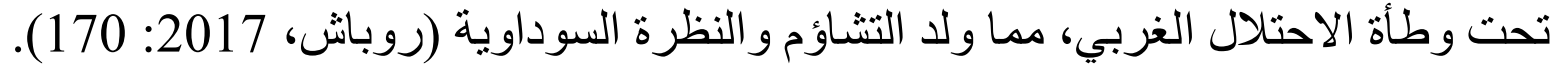

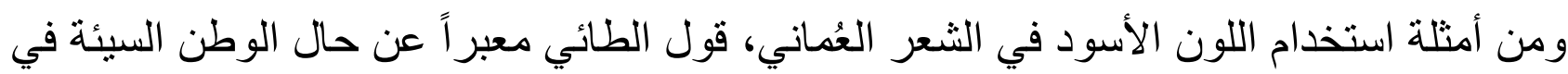

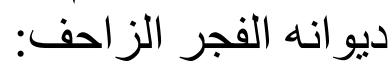

$$
\text { في موطن أحو اله سوداء حالكة السو اد أبناؤه بين اغتر اب و اضطهاد }
$$

قائمة المراجع:

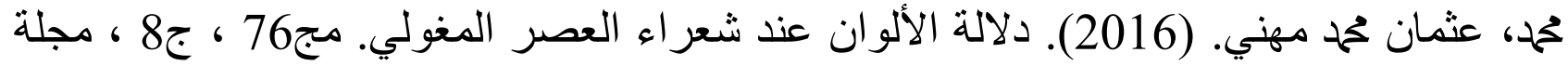
كلية الآداب، جامعة القاهرة.

روباش، جميلةز (2017). دلالة الألوان في شعر محمود درويش، ع8، هله مجلة تاريخ العلوم، جامعة زيان عاشور الجلفة.

حسن، خالد صكبان. (2018). دلالة الألوان في الثعر العربي القديم. ع ع 27، مجلة دراسات

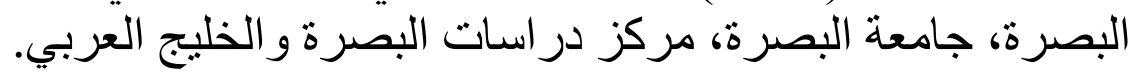

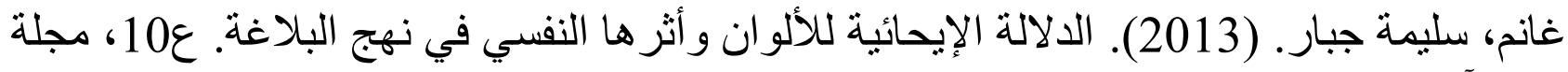

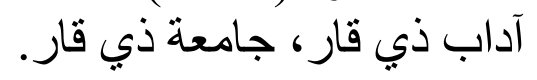

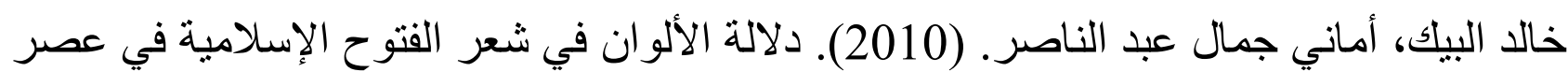
صدر الاسلام. رسالة ماجستير، كلية الآداب ـ الجامعة الاسلامية. شاع الدين، عمر محمد الحسن. (1999). معجم ألفاظ الألوان في اللغة العربية. رسالة دكتور اهاه

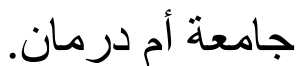

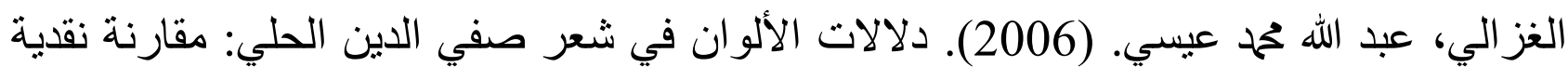

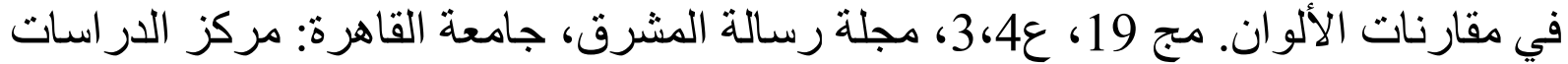
الثرقية.

\section{ARABIC REFERENCES IN ROMAN ALPHABET}

Muhamad, Euthman Muhamad Mahni (2016), Dalalat Al'alwan Eind Shueara' Aleasr Almughwalii, Mjld 76 , Jazaa 8 , Majalat Kuliyat Aladabi, Jamieat Alqahirat.

Rubash, Jamila (2017), Dalalat Al'alwan fi Shaear Mahmud Darwish, add 8, Majalat Tarikh Aleulumi, Jamieat Ziaan Eashur Aljilfat.

Hasan, Khalid Sikban (2018), Dalalat Al'alwan fi Alshier Alearabii Alqadiimi, add 27, Majalat Dirasat Albasrat, Jamieat Albasrat, Markaz Dirasat Albsrt Walkhalij Alearabi.

Ghanm, Salimat Jabaar (2013), Aldalalat Al'iihayiyat Lil'alwan Wa'athariha Alnafsii fi Nahj Albalaghati, add10, Majalat Adab Dhi Qari, Jamieat Dhi Qar.

Khalid Albayka, 'Amani Jamal Eabd Alnnasir (2010), Dalalat Al'alwan fi Shaear Alfutuh Al'iislamiat fi Easr 
Sadar Alaislam, Risalat Majstir, Kuliyat Aladab - Aljamieat Alaislamiat.

Shae Aldiynu, Eumar Muhamad Alhasan (1999), Maejam 'Alfaz Al'alwan fi Allughat Alearabiati, Risalat Dukturahu, Jamieat 'Am Dirman.

Alghizali, Eabd Allah Muhamad Eisy(2006), Dilalat Al'alwan fi Shaear Sifii Aldiyn Alhuly: Mqarnt Naqdiat Fi Muqaranat Al'alwani, Maj 19, add 3,4, Majalat Risalat Almashriq, Jamieat Alqahirat - Markaz Aldirasat Alsharqiat. 